\title{
Cómo diseñar edificios sagrados a comienzos del primer milenio a. C. en la península ibérica. El uso del triángulo $3 / 4 / 5$ y de los triángulos isósceles por los arquitectos/maestros de obra fenicios en La Rebanadilla, Málaga
}

\author{
How to design sacred buildings on the Iberian \\ Peninsula at the beginning of the first millennium BC. \\ The use of the 3/4/5 triangle and isosceles \\ triangles by the Phoenician architects/master \\ builders on La Rebanadilla, Málaga
}

\author{
VICENTE MARCOS SÁNCHEZ SÁNCHEZ-MORENO \\ Arqueoestudio S.Coop. \\ Calle Manuel Cano 1, Local, 28007 Madrid \\ info@arqueoestudio.com \\ https://orcid.org/0000-0002-4916-1767
}

\begin{abstract}
Resumen
En este artículo presentamos nuestras ideas sobre el diseño de los edificios religiosos fenicios arcaicos de la península ibérica. La observación de las dimensiones de los diferentes espacios del complejo religioso fenicio de La Rebanadilla, Málaga, en donde se repiten medidas, como las que conforman rectángulos de 3 por 4 metros de lado, nos llevó a plantearnos cuáles eran los conceptos en el diseño de los diferentes edificios de este enclave y cómo estos eran llevados desde el plano al terreno. Para ello, partimos de que estos rectángulos se forman por dos triángulos rectángulos múltiplos de los triángulos pertenecientes al grupo 3/4/5 (triángulos construidos por medio de números enteros consecutivos y que cumplen con el teorema de Pitágoras, presentes en la arquitectura egipcia desde la construcción de las pirámides), así como de los triángulos isósceles construidos a partir de los triángulos rectos $3 / 4 / 5$.
\end{abstract}

Palabras clave: arquitectura fenicia, diseño, geometría, triángulo 3/4/5

\section{Abstract}

In this article, we present our ideas about the design of archaic Phoenician religious buildings on the Iberian Peninsula. The observation of the dimensions of the different spaces of the Phoenician religious complex of $\mathrm{La}$ Rebanadilla, Málaga, where measurements are repeated, such as those that make up rectangles of 3 by 4 meters on a side, led us to consider the concepts in the design of the different buildings on this settlement, and how they were taken from the drawing to the ground. For that, we start from the fact that these rectangles are formed by two right-angled triangles multiple of triangles belonging to the group 3/4/5 (triangles built by consecutive integers that keep to the Pythagorean theorem, present in Egyptian architecture since the construction of the pyramids), as well as the isosceles triangles built from the $3 / 4 / 5$ right-angled triangles.

Key words: Phoenician architecture, design, geometry, 3/4/5 triangle 


\section{Introducción}

La Rebanadilla se localiza en el término municipal de Málaga, a $3 \mathrm{~km}$ de la actual línea de costa y en la margen derecha del encauzamiento del río Guadalhorce, sobre una paleo-isla (Sánchez et alii, 2011: 187; 2020: 189; Arancibia et alii, 2011: 130) del antiguo estuario del río (Aubet et alii, I999: 33-4I). Dista más de $7 \mathrm{~km}$, al suroeste, del centro histórico de la ciudad malagueña (figura I).

Por medio de la estratigrafía, de los materiales crono-marcadores recuperados - principalmente cerámicos- y de las dataciones absolutas (Sánchez et alii, 20II: 187-193; 2012: 68-70; Arancibia et alii, 20Ir: 130), se pudieron definir cuatro grandes fases crono-culturales:

- Fase IV (segunda mitad del siglo Ix a. C.): correspondiente a la instalación de sendos talleres de marfil, de fabricación de materiales constructivos, y metalúrgico.

- Fase III (segunda mitad-finales del siglo IX a. C.): donde se articula la construcción, uso y abandono del primer complejo religioso de La Rebanadilla.

- Fase II (finales del siglo IX a. C.-principios del siglo vin a. C.): relacionada con la edificación, en la zona oriental del yacimiento, de un posible segundo complejo ritual, levantado sobre los escombros de la fase anterior, observándose un cambio en la técnica constructiva.

- Fase I (principios del siglo viII a. C.): correspondiente a la reutilización del solar del antiguo complejo religioso como zona de talleres, en especial, metalúrgicos.

El presente trabajo analiza los diferentes edificios que conforman el complejo religioso de la Fase III (finales del siglo ix a. C.) de La Rebanadilla, Málaga (Sánchez et alii, 20II; 20I2; 20I8 y 2020) (figura 2).

En anteriores publicaciones (Sánchez et alii, $20 \mathrm{I} 2 \mathrm{y}$ 2018), nos hemos aproximado a las características generales de la arquitectura de La Rebanadilla, con una descripción de algunos de sus espacios más significativos.

Cuando comenzamos a trabajar con las diferentes construcciones que conforman el yacimiento en su Fase III, observamos que se repetían proporciones y medidas, tanto en los edificios como en las habitaciones en las que se compartimentan: principalmente rectángulos de $3 \times 4 \mathrm{~m}, \mathrm{y}$ de $6 \times 4 \mathrm{~m}$ para los conjuntos de dos habitaciones. Estas dimensiones, en algunos casos, se daban intramuros, tras excluirse ciertos elementos arquitectónicos auxiliares como bancos corridos, pilastras o escaleras de entrada.

Una reflexión sobre estas medidas nos hizo pensar en la utilización del triángulo $3 / 4 / 5$, o «Triángulo Sagrado» (Martínez, 20or: 7) y sus múltiplos, para la generación de los espacios rectangulares que configuran estos edificios; así como el uso del módulo correspondiente al codo fenicio para su diseño y construcción.

Uno de los objetivos generales de la investigación realizada sobre La Rebanadilla fue la identificación de los protagonistas de la fundación de este emplazamiento, tanto los arribados desde Oriente, como los locales. Este trabajo nos ha permitido identificar a uno de ellos, el maestro de obra y/o arquitecto, entendido como el personaje que tiene los conocimientos necesarios para la organización del trazado urbano; para el diseño de los edificios y su traslación desde un boceto, o idea, al terreno; para el control de los talleres necesarios para la obtención de las materias primas y su transformación en elementos imprescindibles para la edificación y para la organización de la mano de obra implicada. Este maestro de obra y/o arquitecto sería, por tanto, un personaje llegado desde Oriente, con conocimientos inéditos en Occidente hasta esos momentos, y que será clave en el devenir del asentamiento fenicio en la península ibérica.

Los maestros de obra y/o arquitectos no han sido, hasta ahora, fuente de estudio, siendo escasos los trabajos existentes sobre ellos, como ya comentaba Díes Cusí (1994) en su tesis doctoral, no habiendo variado mucho esta realidad en el último cuarto de siglo. No obstante, las fuentes antiguas tampoco aportan datos sobre ellos, como también comenta Díes Cusí, sobre todo en lo referente a los fenicios. Solo tenemos reseñas sobre estos personajes en Egipto, como por ejemplo Imhotep, actor relevante del III milenio a. C. por su amplio espectro de conocimientos en medicina, astronomía, arquitectura e ingeniería; por pertenecer al orden sacerdotal y por sus cargos 


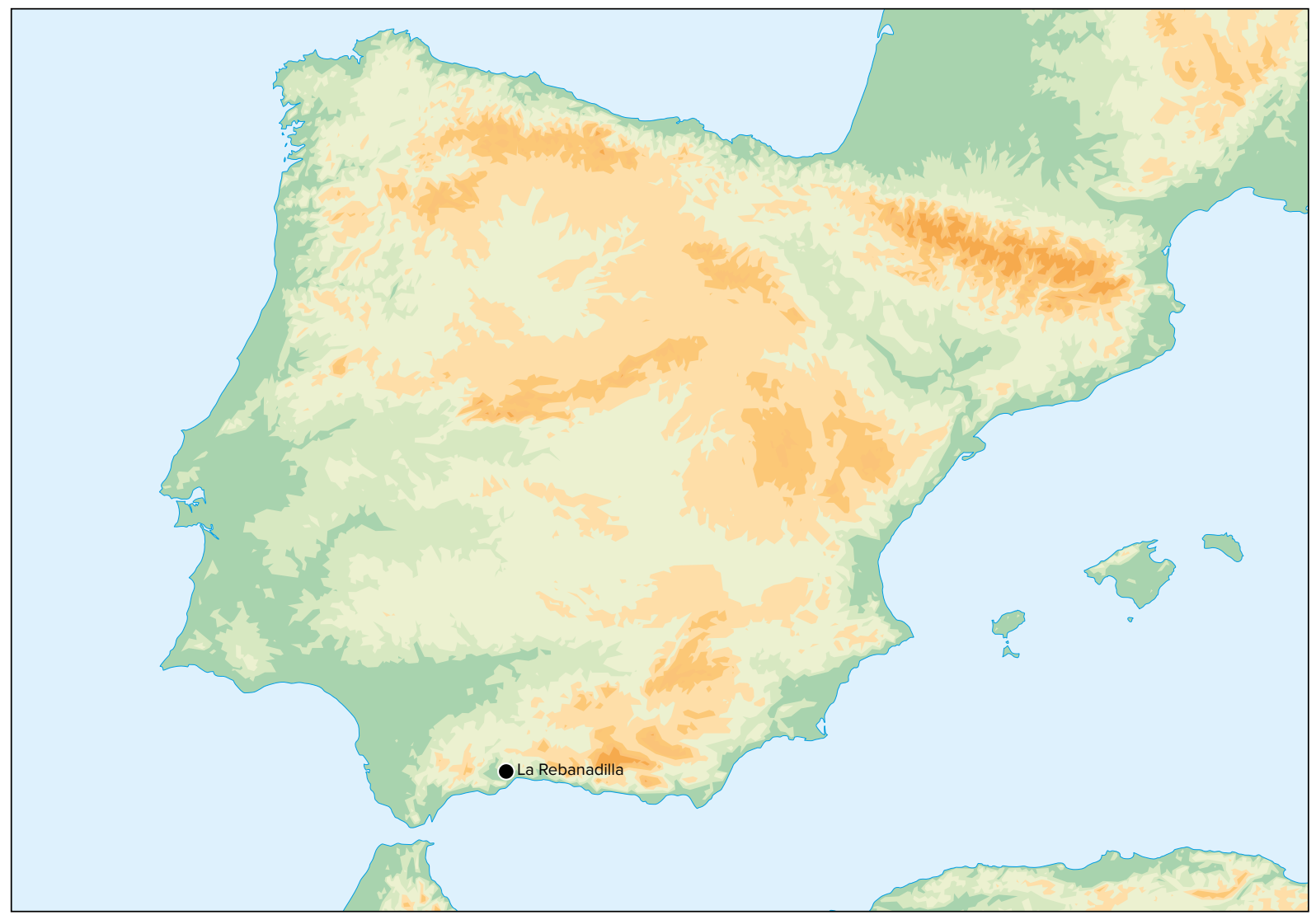

Figura 1. Ubicación de La Rebanadilla en la península ibérica

Figure 1. Location of La Rebanadilla in the Iberian Peninsula

palaciales. Esta relación entre arquitecto, palacio y templo es interesante para entender la fuente de conocimiento de estos personajes y su importancia en el proyecto de generación de un espacio sagrado en el otro extremo del mundo conocido por los fenicios orientales.

Vitruvio, dos milenios y medio después, en su Libro I, capítulo primero "Qué es Arquitectura y qué cosas deben saber los arquitectos», hace hincapié en la necesidad de un conocimiento amplio en diferentes materias, por parte de los arquitectos, para poder llevar a buen término sus proyectos:

Para lograrlo es preciso tener talento y afición al estudio; puesto que ni el talento sin estudio, ni el estudio sin talento, pueden formar un buen arquitecto. Debe, pues, este estudiar Gramática; tener aptitudes para el Dibujo; conocer la Geometría; no estar ayuno de Óptica; ser instruido en Aritmética y versado en Historia; haber oído con aprovechamiento a los filósofos; tener conocimientos de
Música; no ignorar la Medicina; unir los conocimientos en la Jurisprudencia a los de Astrología y movimientos de los astros.

Estos dos ejemplos, distantes en el tiempo, a los que podríamos añadir los sabios constructores griegos del primer milenio a. C., nos muestran la importancia de poseer destrezas en diversas materias para poder ejecutar los proyectos constructivos. Nuestro personaje debería estar versado en diferentes áreas de conocimiento y, por tanto, estar vinculado a los espacios de sabiduría de la antigüedad, como serían los templos o complejos religiosos, en donde se atesoraba y guardaba, en gran medida, la información que se recababa y recopilaba de comerciantes, peregrinos, peticionarios o penitentes que acudían a estas instalaciones.

A pesar de lo poco excavado de La Rebanadilla, el azar o la fortuna quiso que se pudieran identificar, dentro de la Fase III, dos edificios interpretados como templos, otras dos habitaciones reconocidas como capillas, y una sala en donde se realizó un 


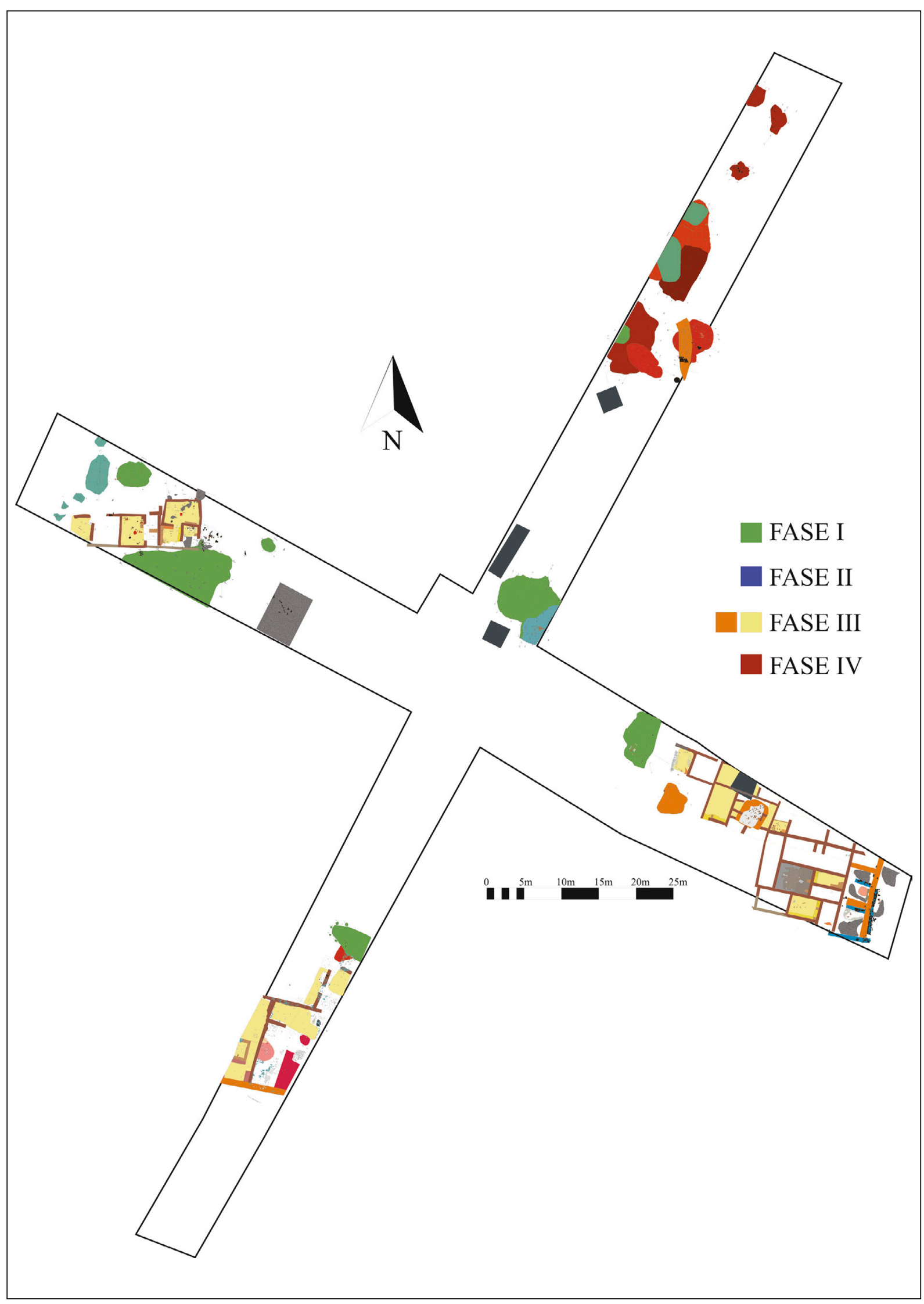

Figura 2. Planimetría de La Rebanadilla con fases cronológicas

Figure 2. Planimetry of La Rebanadilla with chronological phases 
último banquete -entre unos pocos personajes de alto rango-, antes del abandono ritual de la instalación. Junto a estas, también se excavaron, o identificaron - a falta de profundizar en su interior- otro edificio completo y tres más, de forma parcial, que interpretamos como auxiliares.

De forma genérica, el complejo religioso de la Fase III de La Rebanadilla se corresponde con la segunda fase de ocupación de este emplazamiento. En la Fase IV, previa, es cuando se documenta la presencia de, al menos, un taller metalúrgico (Sánchez et alii, 20II: I87-I88; 20I8: 320), y otro para el trabajo del marfil (Marzoli et alii, 2or6), al tiempo que debería estar en funcionamiento un tercer taller dedicado a materiales de construcción, y encargado de realizar los preparativos (elaboración de arcillas, fabricación de adobes, adquisición de maderas, etc.) para la edificación del complejo religioso. Esta fase es corta en el tiempo, pero desde nuestro punto de vista, básica para el emplazamiento.

Entendemos esta fase como de pago, por parte de la aristocracia oriental a la aristocracia malacitana, para el establecimiento del santuario. Una fase de negociación entre las casas reales orientales y las casas «reales» locales; es decir, fruto de una relación entre iguales (López Castro, 20I2: 93) donde ambas partes disponen del territorio, $y$ de las personas bajo su control, para conseguir sus fines. Por tanto, entre las personas procedentes del Mediterráneo Oriental, debería haber llegado alguien con autoridad suficiente como para materializar este tratado.

Estos pactos fueron definidos por Arteaga como «pactos de servidumbre» (Arteaga, 200r: 234-235), en donde se intercambiaba tierra por personal especializado y cualificado; en nuestro caso, los artesanos que se establecen inicialmente en La Rebanadilla, donde los elementos que producen in situ estarían destinados a satisfacer las necesidades de las poblaciones locales. Esta idea de intercambio de fuerza de trabajo especializada entre las élites también ha sido expresada por López Castro (2005: 4I2), poniendo como ejemplo la construcción del templo de Jerusalén entre Hiran I de Tiro y Salomón de Israel (I Reyes 5, II).

En otros complejos religiosos coetáneos a $\mathrm{La}$ Rebanadilla, como son El Carambolo (Camas, Sevilla) (Fernández y Rodríguez 2007; Hunt Ortiz et alii, 2010) y el localizado en el solar entre la calle Méndez Núñez y la plaza de las Monjas de Huelva (Osuna et alii, 2000; González de Canales et alii, 2004), parecen repetirse estos procesos, ya que se documentan, igualmente, talleres precedentes a los complejos religiosos.

Es posible que los propios maestros de obra/arquitectos orientales, una vez construidos los complejos fenicios en Occidente, hayan sido transferidos, en virtud de estas relaciones, a las elites locales para que edifiquen para ellos, como atestiguarían los edificios de características orientales presentes en los yacimientos locales coetáneos, como Castillejos de Alcorrín (Manilva, Málaga) o el templo de Castro dos Ratinhos (Moura-Alqueva, Portugal). Ya López Pardo (1990: 161) exponía que Cancho Roano «sería seguramente una de las máximas expresiones de regalo inmueble fenicio a un jefe local».

En La Rebanadilla, la fundación del complejo religioso y el comienzo de las obras se atestigua en un banquete ritual colectivo. Este ritual, en el que participa tanto la población local como la recién llega$\mathrm{da}$, se ve reflejado en las vajillas utilizadas (Sánchez et alii, 2018: 313-314 y 2020) y abandonadas en el interior de un pozo, cuya amortización ritual, con los restos del banquete, se verá directamente afectada por la zanja de cimentación del muro perimetral que delimitará el espacio sagrado.

Podemos entender la construcción de este complejo religioso, promovido por la casa real, como un intento de demarcación del área del territorio de la metrópolis, como habla Kamlah (2009: 86) para la ciudad de Sidón, pero realizándose al otro extremo del mundo conocido.

\section{2. $3 / 4 / 5$, la base del diseño fenicio}

La documentación de tres edificios, más o menos completos, en La Rebanadilla, nos ha permitido estudiar sus proporciones y módulos, deparándonos sorpresas sobre su diseño.

Si bien algunas de las técnicas ya podrían encontrarse en la península ibérica, como la conformación de espacios rectangulares - documentados en la Edad del Bronce del suroeste de Andalucía 
y en el Bronce Argárico (Escacena, 20r6: 50)—, o la utilización de tierra como material constructivo -frecuente en los yacimientos de la Prehistoria reciente peninsular-, sus conocimientos van más allá Los adobes se encuentran estandarizados en métrica, aproximadamente $30 \times 45 \mathrm{~cm}$, si bien esta puede variar entre los diferentes yacimientos y momentos crono-culturales y, para su producción, será necesaria la implantación e implementación de talleres encargados de su moldeado y secado. Pero además, la gran aportación que introducen los maestros de obra/arquitectos, encargados del diseño de los edificios, es su planteamiento, por medio de la Geometría, a través del triángulo $3 / 4 / 5 \mathrm{y}$ sus derivados, que posteriormente podrá ser transportado al terreno mediante la cuerda o escuadra de los i2 nudos. Este triángulo estaría presente en el diseño y construcción de las pirámides de la IV-VI dinastías (Martínez, 200I).

El triángulo $3 / 4 / 5$ se construye por medio de números naturales, enteros y consecutivos que, como es lógico, cumple la regla de los triángulos rectángulos pitagóricos desarrollada con posterioridad. Este planteamiento también será válido para sus múltiplos 6/8/10, 9/12/15, etc.

Las nociones sobre la construcción de triángulos rectángulos eran ya conocidas en el segundo milenio a. C. por los babilónicos, como demuestra la tablilla Plimpton 322 (Benito Muñoz et alii, 2004), en donde se desarrollan series de números para la generación de triángulos rectángulos que cumplen con la ley pitagórica, denominadas ternas pitagóricas. No entraremos aquí en el debate sobre si este conocimiento en los maestros constructores/arquitectos fenicios que arribaron a la Península, era empírico o teórico; solo en si lo poseían.

Sobre la trasposición de los ángulos rectos al terreno para la conformación de espacios rectangulares, Escacena (20I6: 48-49), en su aproximación a la cuerda «sin fin», nos da la clave, a través de los textos recogidos por Montet (1964), sobre las funciones de los faraones en la construcción de los templos, siendo una de estas la del tensado de la cuerda «sin fin»; y por Belmonte (1999: 154) quien habla sobre la importancia que tenía esta técnica en la orientación de los edificios. Por último, Rossi recoge también este ritual atestiguado en varias estelas (Rossi, 2007: I48-I53).
Esta cuerda «sin fin» de los textos egipcios posiblemente se corresponda con la cuerda de I2 nudos y, por tanto, sea la técnica topográfica que permite trasportar el ángulo recto del diseño ideal al terreno. El procedimiento comenzaría clavando dos estacas, distanciadas cuatro nudos entre ellas, orientadas al punto cardinal, o punto singular, al que queramos alinear el edificio. A continuación, al igual que hacía el faraón, se tensa la cuerda, disponiendo cinco nudos desde el extremo alejado y tres desde el más próximo. De esta forma conseguimos trasponer el triángulo $3 / 4 / 5$ al terreno. Igualmente se podría hacer distanciando solo tres nudos las estacas y tirando del nudo situado en posición cuarta desde la estaca más cercana, haciendo de esta forma la habitación más ancha que larga. Una vez tensado el triángulo, nos dará la ubicación de dos de las paredes en ángulo de $90^{\circ}$. Repetimos este proceso, esta vez teniendo como referencia las estacas clavadas en la hipotenusa.

Vitruvio (L, IX, «Introducción») atribuye a Pitágoras la invención de una escuadra para la realización de ángulos rectos, contándonos cómo se construye por medio de tres reglas de 3, 4 y 5 pies, respectivamente. Aunque esta técnica, según Rossi (2007: 154-159), era ya conocida por los egipcios, la autora defiende que no sería posible su uso en el trazo de pequeñas edificaciones, ya que comportaría serios errores motivados por el grosor de cuerdas y nudos (salvo en pequeñas excepciones como la construcción de la bóveda elíptica de la XX dinastía).

El estudio que presentamos a continuación comenzó de forma empírica, mediante ensayo y error, al intentar modelizar el diseño de las construcciones de La Rebanadilla en base a triángulos 3/4/5 sobre la planta de los edificios una vez comprobada, como habíamos dicho con anterioridad, la repetición de medidas en los rectángulos que conformaban las diferentes construcciones documentadas $(3 \times 4 \mathrm{~m}$ y $6 \times 8 \mathrm{~m})$.

Lo primero que tuvimos en cuenta fue que nuestras actuales unidades de medida no tenían que ver con las utilizadas por los diseñadores de estas construcciones. Aun así, nos sorprendía que nuestras medidas, más o menos ajustadas, correspondían a números enteros en metros, lo que hizo plantearnos que el módulo del codo fenicio, para estas, debería ser cercano a los $0,50 \mathrm{~m}$, y que las medidas del 


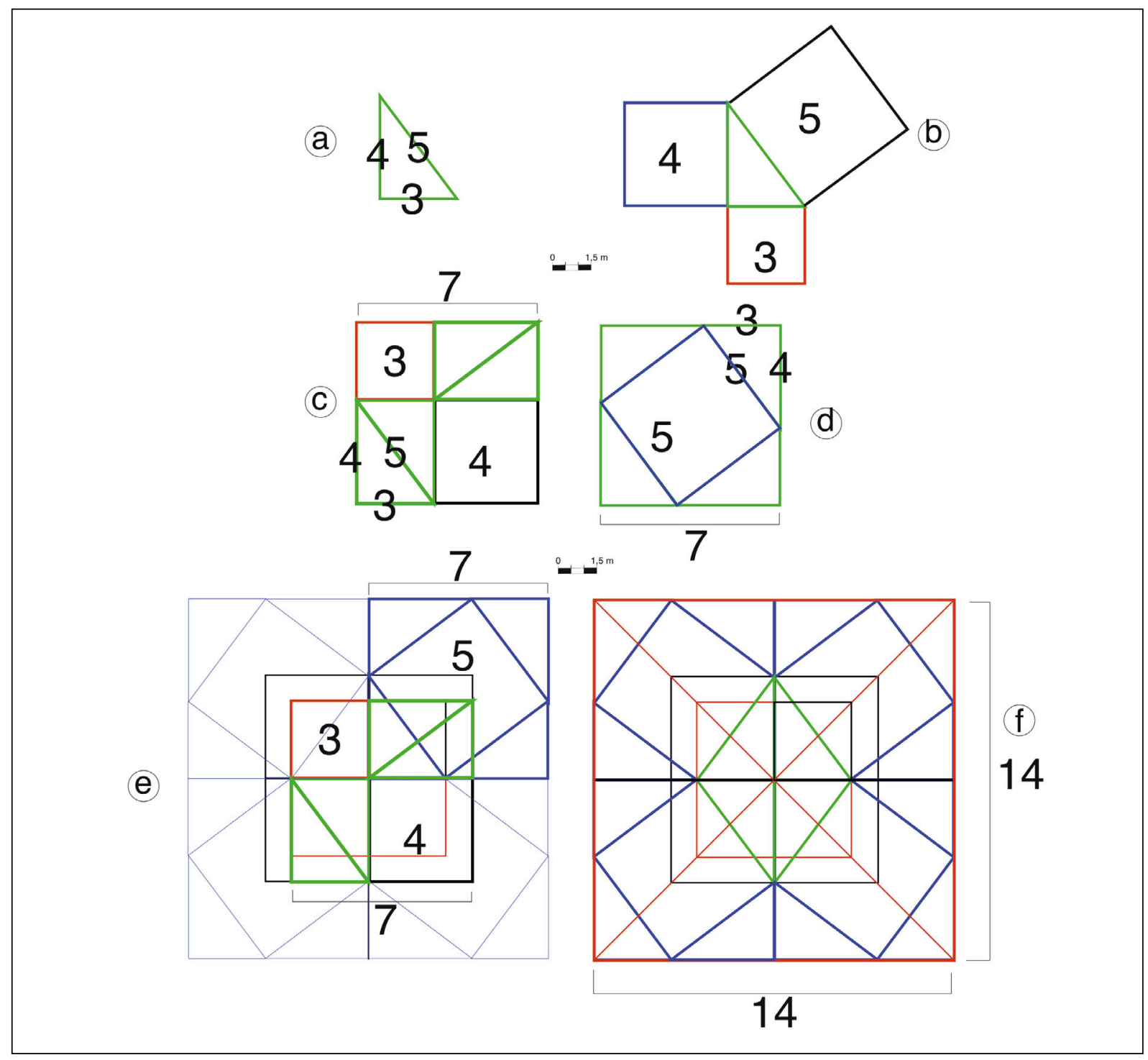

Figura 3. Triángulo rectángulo $3 / 4 / 5$

Figure 3. 3/4/5 right-angled triangle

triángulo $3 / 4 / 5$, en codos fenicios, equivaldrían a $1,5 / 2 / 2,5$ metros. Por medio de este sistema observamos que podíamos determinar la equivalencia entre metros y codos fenicios para los edificios estudiados de La Rebanadilla.

El análisis de estos edificios revelaba que los diseños eran mucho más complejos de lo esperado, al existir pautas para la compartimentación del interior y para la ubicación de los elementos con carga simbólica. Para ello, los maestros de obra/arquitectos fenicios utilizaron, como base de sus diseños, figuras generadas a partir del triángulo $3 / 4 / 5$ : como el polígono en forma de aspa, construido con los cuadrados de los lados del triángulo 3/4/5 (figura 3); o la estrella construida con cuatro triángulos isósceles, desarrollados a partir del triángulo rectángulo $3 / 4 / 5$ (figura 4 ).

\subsection{El polígono en forma de aspa}

El polígono en forma de aspa tiene su génesis en una de las demostraciones geométricas del teorema de Pitágoras (figura 3, c, d y e). Tradicionalmente, los cuadrados generados a partir de los lados del triángulo $3 / 4 / 5$ se han utilizado con tal fin, ya que el cuadrado realizado a partir de la hipotenusa es igual, en área, a la suma de las áreas de los cuadrados construidos con los catetos o, lo que es lo mismo, $\mathrm{a}^{2}+\mathrm{b}^{2}=\mathrm{c}^{2}$. 
Geométricamente, esta equivalencia se demuestra debido a que el cuadrado de 5 de lado, más cuatro triángulos, iguales al originario, colocados en los lados del cuadrado por su hipotenusa, nos conformaría un nuevo cuadrado de 7 de lado (figura $3, d$ ). Del mismo modo, los dos cuadrados de lado igual a los catetos colocados tocándose en una diagonal que atraviesa dos de los ángulos de cada uno de ellos, mas cuatro triángulos iguales al originario, nos genera un cuadrado de 7 de lado (figura 3, c). La demostración, por tanto, sería que, si quitamos de ambas áreas las correspondientes a los cuatro triángulos, el área resultante sería la misma.

La figura en forma de aspa nace del triangulo $3 / 4 / 5$ más los tres cuadrados colocados en cada uno de sus lados (figura 3, b). Esta figura la repetimos cuatro veces, uniéndolas por los lados del triángulo que conforma el ángulo recto, dándonos como resultado una figura con forma de aspa (figura $3, \mathrm{e}$ ) que, en su centro, tendrá un rombo conformado por los cuatro triángulos $3 / 4 / 5$, y dos cuadrados concéntricos: uno de 6 de lado, construido a partir de los cuatro cuadrados de 3 de lado; y otro de 8 formado por medio de los cuatro cuadrados de 4 de lado. Este polígono podemos inscribirlo en el interior de un cuadrado de I4 de lado, delimitado por los ángulos exteriores de los cuadrados de 5. Si trazamos los dos ejes de simetría, perpendiculares a los lados, que pasan por el baricentro de este cuadrado de I4, nos dejan a la vista cuatro cuadrados de 7 , con el cuadrado de 5 inscrito en su interior junto a los cuatro triángulos originales $3 / 4 / 5$ (figura $3, \mathrm{f}$ ).

Por medio de este modelo obtenemos cuadrados de 3, 4, 5, 6, 7, 8 y I4 de lado que, además de delimitar los volúmenes exteriores de los edificios o, por lo menos de parte de ellos, sirven para configurar las distribuciones interiores de las salas que pueden componer tales construcciones, así como la ubicación de elementos con características especiales, como son las mesas/altar o los hogares/altar.

\subsection{El polígono en forma de estrella}

Otra de las formas geométricas utilizadas nace del triángulo isósceles, en especial el de 8 de base y de altura, y sus múltiplos y divisores. Este triángulo se relaciona con el triángulo $3 / 4 / 5$, en el que, si colocamos un triángulo de $3 / 4 / 5$ en la base del triángulo isósceles, posicionando el cateto de 4 de lado sobre la base, y el cateto de 3 de lado sobre el eje de simetría - que en este caso coincide con la mediana trazada desde la base-, el vértice de este último cateto con la hipotenusa del triángulo rectángulo se sitúa sobre el circuncentro del nuevo triángulo isósceles, que estaría inscrito en un circulo de ro de diámetro (figura 4.I).

El triángulo isósceles es, normalmente, utilizado para la generación de los volúmenes exteriores y la compartimentación de los espacios interiores, mediante la construcción de una estrella formada por cuatro triángulos, colocados en ángulo recto con respecto al siguiente, que comparten el circuncentro (figura 4, b y c) y que, por lo tanto, están inscritos en el mismo círculo. Las bases de los cuatro triángulos generarían dos rectángulos de $8 \times 6$ de lado (figura $4, \mathrm{~d}$ y e). Si la equivalencia es de un metro para dos codos, las dimensiones de los triángulos isósceles construidos con un triángulo rectángulo de $\mathrm{I}, 5 / 2 / 2,5$ metros, o $3 / 4 / 5$ codos, es de $4 \mathrm{~m}$ de alto por $4 \mathrm{~m}$ de base, estando inscrito en un círculo de $5 \mathrm{~m}$. Estas son las dimensiones de la estrella que podemos considerar como «módulo» (figura 4 e y f), a partir de la cual se crean los múltiplos y divisores.

\section{Análisis de los edificios de La Rebanadilla}

\subsection{Habitaciones de $6 / 8 / 10$}

Como hemos mencionado, en La Rebanadilla existen varias habitaciones cuya morfología se corresponde con la del rectángulo de $6 \times 8 \operatorname{codos}(3 \times 4 \mathrm{~m})$, pero de las que no poseemos la planta completa del edificio en donde se localizan.

Los dos mejores ejemplos son dos salas con marcado carácter ritual o religioso: la primera de ellas, se corresponde con la Capilla 2 (figura 5, b) (Sánchez et alii, 20I8: 3II), localizada en el Edificio 7 situado al oeste del Edificio 5 o Templo 2. El rectángulo de $6 \times 8 \operatorname{codos}(3 \times 4 \mathrm{~m})$ lo encontramos en el interior de la sala. Los elementos más significativos 
(a)

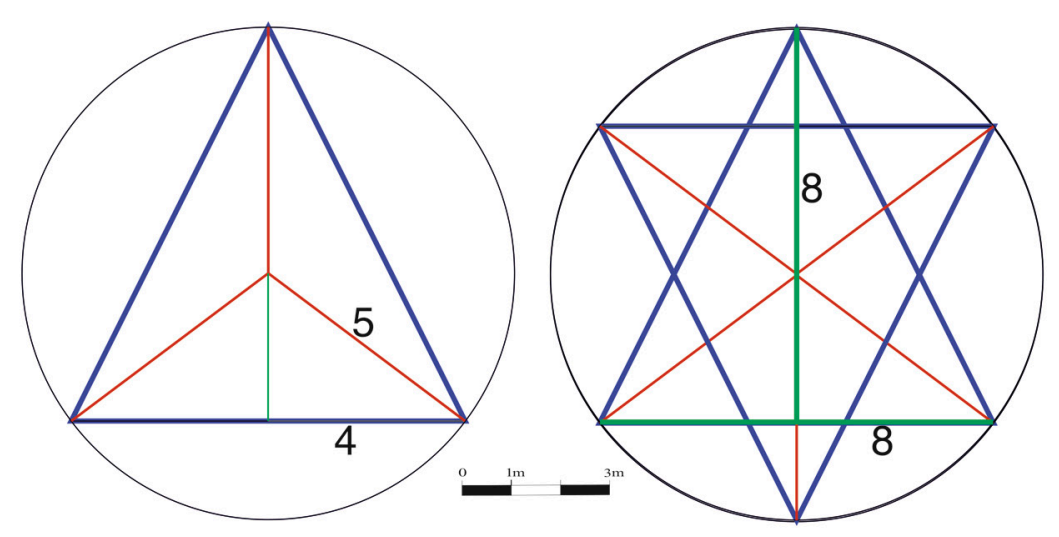

(b)

(C)
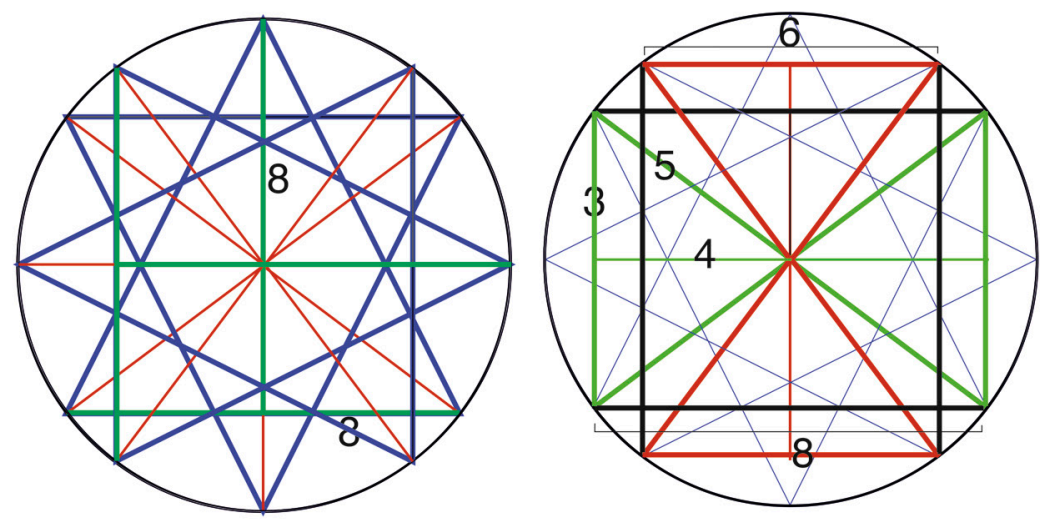

(d)

(e)
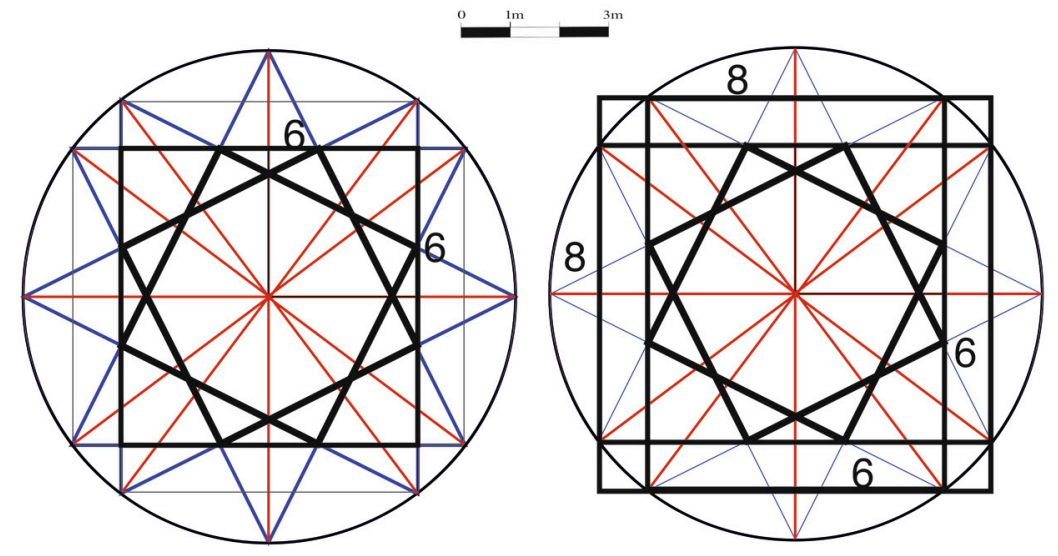

Figura 4. Triángulo isósceles

Figure 4. Isosceles triangle

de la habitación se corresponden con un banco corrido/mesa auxiliar en el muro norte, un refuerzo o pilastra en la esquina noreste, un banco corrido o mesa auxiliar en el muro este, y un hogar circular situado, aproximadamente, en la parte central. Si colocamos la figura en forma de estrella, de tamaño igual al módulo, conformada con los triángulos isósceles, y con el circuncentro en el centro de la sala (figura 5 , e), observamos cómo se definen las diferentes partes de la capilla. El rectángulo de $6 \times 8$, inscrito en la figura de la estrella, orientado norte-sur, nos delimita el espacio interior de la sala; mientras que el otro, orientado este-oeste, nos determina el grosor de los muros laterales, además de definir el límite de la estructura colocada en la cabecera norte (banco corrido/mesa auxiliar). Igualmente, los puntos en donde se cortan los triángulos nos determinan las posiciones de varios de los elementos documentados 


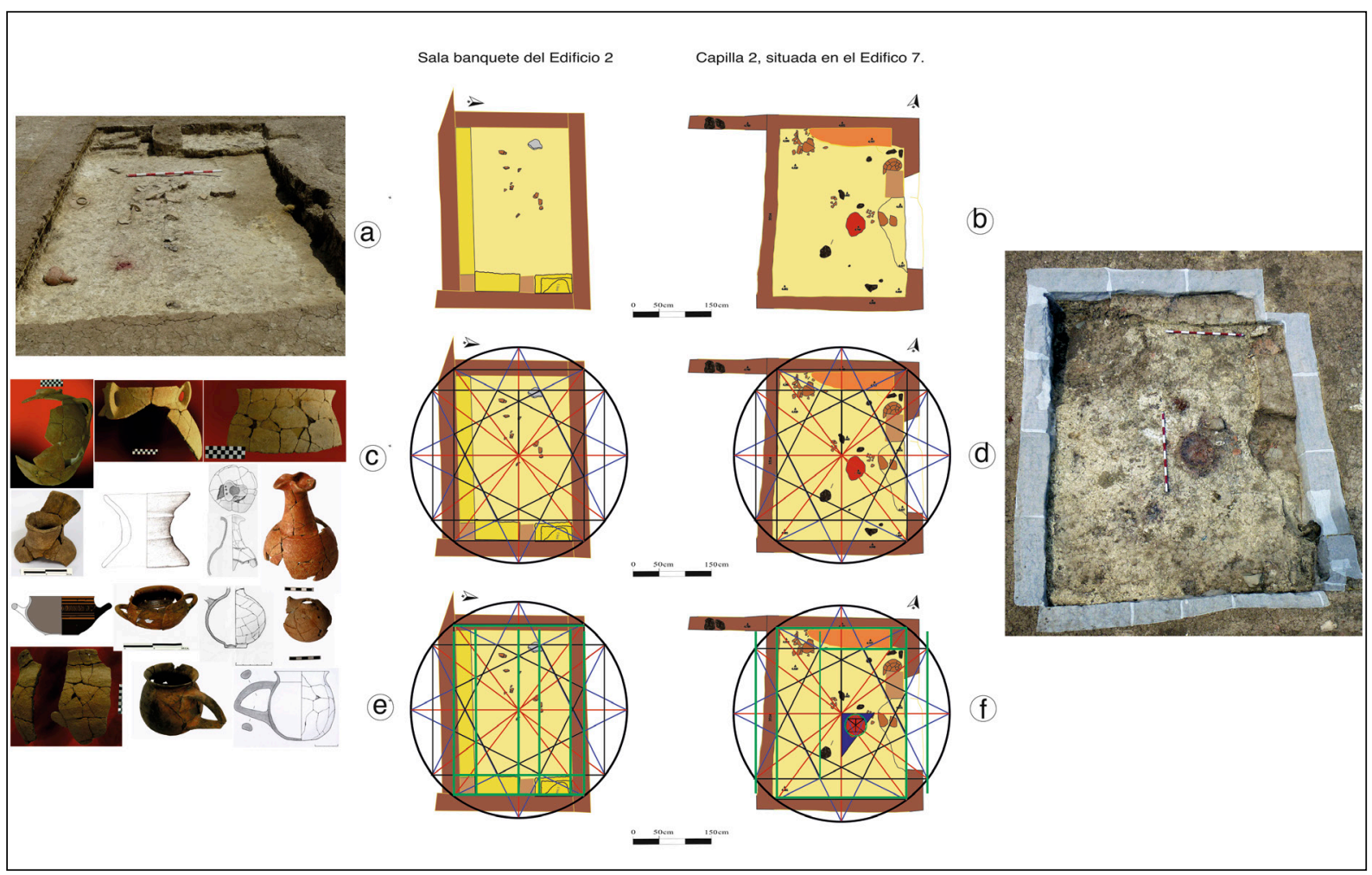

Figura 5. Las habitaciones $6 \times 8$

Figure 5. Rooms $6 \times 8$

en la sala. Entre ellos, destaca la ubicación del hogar/altar que se encuentra tangente a los dos ejes de simetría axial de la sala en su cercanía al punto central. Si trazáramos un triángulo $3 / 4 / 5$ en donde los catetos se sitúan sobre los ejes de simetría, y el vértice que los une se posicionara sobre el centro del rectángulo, este quedaría inscrito en su interior (figura 5 , f). Otra de las características del hogar/altar circular es que su tamaño es una décima parte del círculo que inscribe la figura con forma de estrella.

El segundo ejemplo corresponde a la Sala del Banquete del Edificio 2 (figura 5, a) situada al este del yacimiento. Tiene unas dimensiones interiores, con bancos corridos y mesas auxiliares, de 3,80 $\mathrm{m}$ de largo por 2,48 m. Su suelo estaría formado por un enlucido amarillo, que parece demostrar que esta sala estaría cubierta. Los muros que conforman el espacio se encuentran construidos por macizos de barro y están revocados por enlucidos, también de tonalidad amarilla. Aquí se documentaron dos pilastras, construidas mediante la acumulación de adobes adosados al muro este: la situada más al norte, con unas dimensiones de $0,50 \times 0,34 \mathrm{~m}$; y la más al sur, de $0,46 \times 0,3 \mathrm{I} \mathrm{m}$, que tendrían la función de reforzar la estructura. Entre medias de ellas se sitúa un banco corrido/mesa auxiliar de I $\times 0,5 \times 0,12 \mathrm{~m}$. $\mathrm{E} 1$ acceso se realizaría por la esquina noreste, por una entrada escalonada con dos peldaños: el superior de $0,44 \times 0,37 \mathrm{~m}$, de menor tamaño que el inferior, de $0,54 \times 0,47 \mathrm{~m}$, teniendo ambos una altura de apenas $5 \mathrm{~cm}$. La luz supuesta para la entrada sería de $0,50 \mathrm{~m}$. Adosado a la pared sur se situaría un banco corrido de 3,15 $\times 0,30 \mathrm{~m}$ del que no se conoce su altura al encontrarse desmontada la parte superior.

Si volvemos a utilizar la figura de la estrella como base del diseño, con el circuncentro en el centro de la sala (figura 5, c), observamos cómo esta define los límites de la sala y el grosor de los muros laterales, así como la ubicación de los elementos adosados al paramento este. Es especialmente interesante cómo queda definida la mesa auxiliar que preside la sala, en la que se localizó un carrete sobre el que se colocaría el ánfora del banquete (Sánchez et alii, 20I8: 312-3I3 y 2020: 244), delimitada por el eje de simetría este-oeste, principal de la sala, y por la base del triángulo isósceles orientado al oeste. 


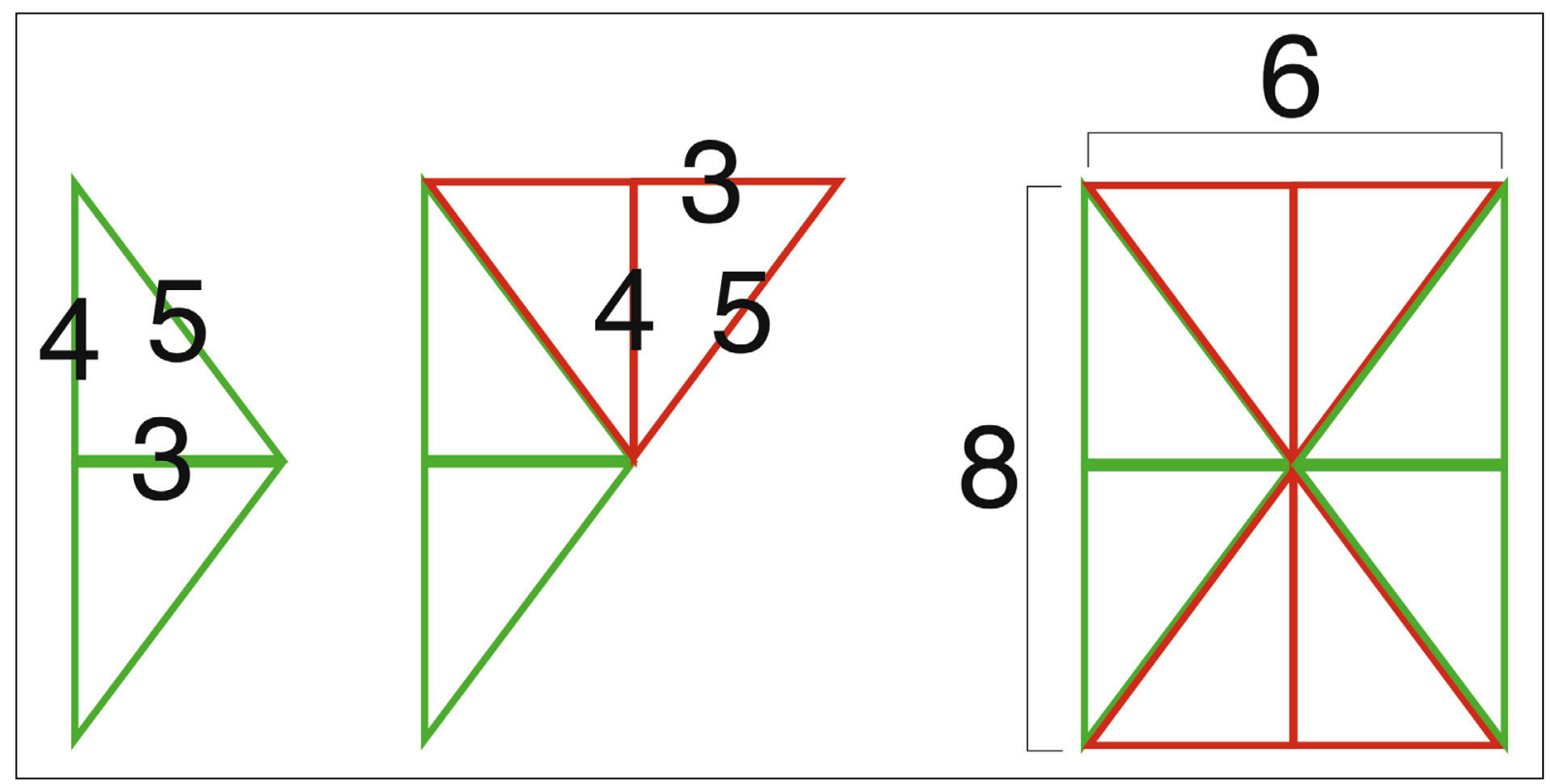

Figura 6. La construcción de los rectángulos 6 × 8 en el terreno

Figure 6. Constructing the $6 \times 8$ rectangles on the ground

Estos rectángulos se podrían construir en el terreno mediante ocho triángulos $3 / 4 / 5$. Cuatro de 4 de lado en la base, y cuatro de 3 de lado en la base (figura 6).

\subsection{Edificio 1}

Denominado como E1 (figura 7, a), con orientación este-oeste, el Edificio 1 se sitúa al este del emplazamiento, junto a la cerca que delimita el témenos. Presenta unas dimensiones interiores, es decir, sin incluir los muros exteriores de la construcción, de II $\times 7 \mathrm{~m}$, equivalentes a $22 \times \mathrm{I} 4$ codos fenicios. $\mathrm{Su}$ área es de $77 \mathrm{~m}^{2}$, estando su interior distribuido en ocho espacios, formados por un patio, cinco habitaciones y dos pasillos o habitaciones alargadas. E1 núcleo principal de la construcción se conforma por un patio y dos habitaciones traseras, que abarcarían una superficie de $28 \mathrm{~m}^{2}$. La construcción se adapta, en su esquina noroeste, a la edificación $\mathrm{E}_{4}$, construida con anterioridad a E1.

Esta construcción se encontraba realizada a partir de macizos de tierra, no presentando ni zócalos ni cimientos, apoyándose los muros directamente sobre el sustrato geológico, con una anchura media en los paramentos de $0,38 \mathrm{~m}$.

De este edificio solo se excavaron dos espacios, quedando visibles, en planta, las demás áreas mencionadas. En las dos estancias excavadas se han documentado, adosadas al muro medianero - entre la estancia del patio y las dos habitaciones traseras-, varias pilastras realizadas apilando adobes de $0,47 \times 0,50 \mathrm{~m}$. El patio central poseía dos lajas, colocadas, a modo de basa, en el eje de simetría este-oeste de la estancia, que se corresponderían con dos elementos sustentadores exentos. Las paredes se encontraban revocadas con lechadas de arcillas amarillas, de composición similar a la de los adobes/macizos de tierra.

Respecto a su funcionalidad, al no documentarse restos relacionados con el ceremonial - a pesar de que su núcleo constructivo, el patio y las dos salas traseras muchas veces se relacionan con templos, como El Carambolo V, y el propio Templo 2 de La Rebanadilla en la Península; o con los templos de Tell Taya o Tell el-Ghasshil (Fernández y Rodríguez, 2007: 219-220; Díes Cusí, 200I: 78), y el «Edificio del Patio con Pilares en el Área N» de Tel Kinrot (Nissinen y Münger, 2009) para el Mediterráneo Oriental-, pudo tener un carácter administrativo o auxiliar, semejante a las viviendas de Tell Keisan Nivel 9a (Briend y Humbert, 1980: fig. 54; Díes Cusí, 20or: fig. 4) y 8a (Díes Cusí, I994: I45 y fig. Iı); a las subdivididas en «T» del nivel IV (Ir25-Iroo-950 a. C.) de Tell Abu Hawam (Díes 


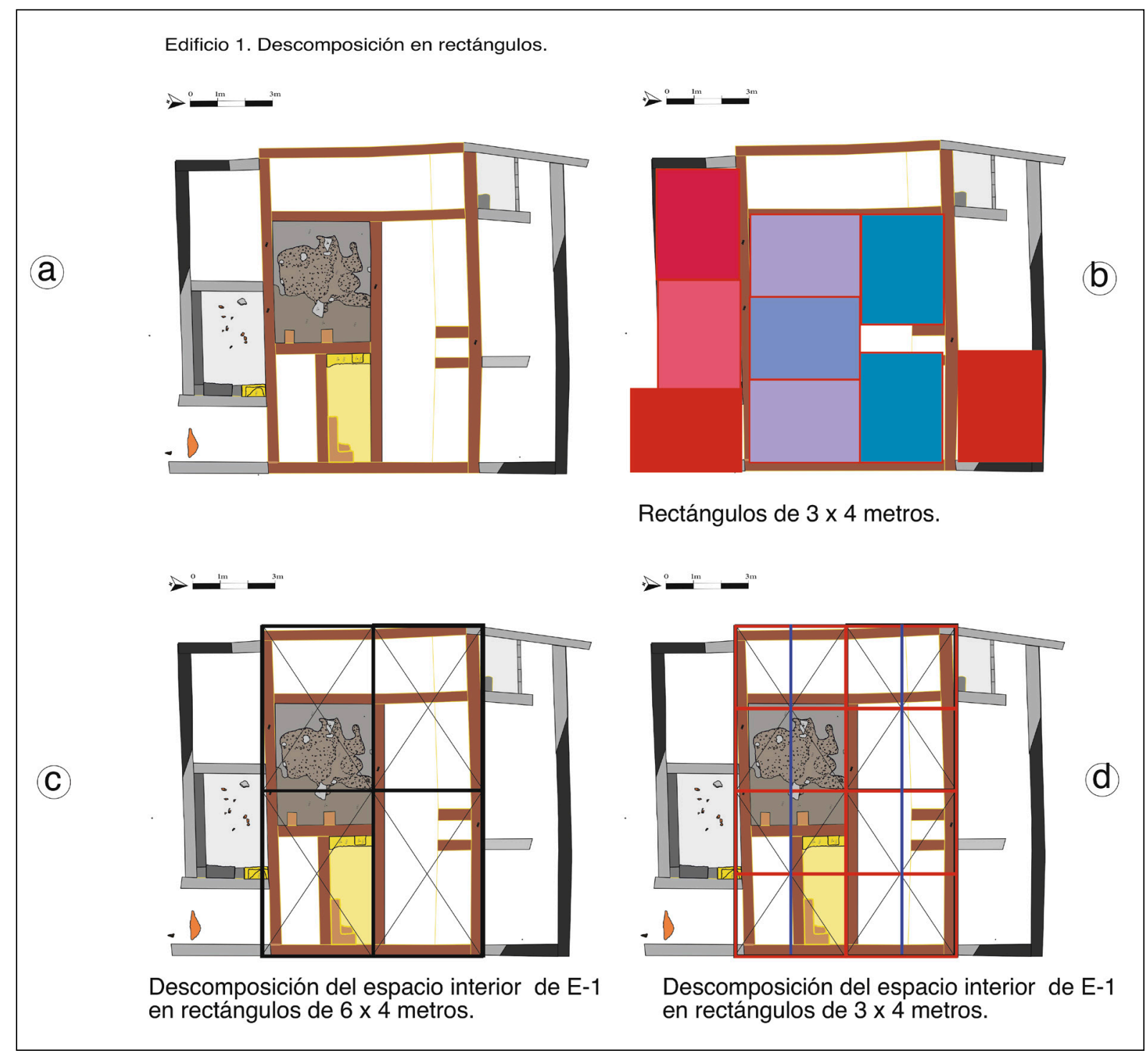

Figura 7. Rectángulos $6 \times 8$ inscritos en el Edificio 1 de La Rebanadilla

Figure $7.6 \times 8$ rectangles inscribed in E1 building of La Rebanadilla

Cusí, 1994: I48 y fig. Ir4); a las casas de los gobernadores egipcios, como el del posible palacio de Bet Sham, Estrato IV (Díes Cusí, 2oor: fig. Ir,C); o, en la Península, a la parte noreste del Edificio 2 del Cerro del Villar, en Málaga (Delgado, 2008). Según la clasificación de Braemer (I982: 39 y ss), para las viviendas de la Edad del Bronce orientales, pertenecería al Tipo IB2.

El edificio E1 podemos inscribirlo en un rectángulo de $\mathrm{I} 2 \times 8 \mathrm{~m}$, que se divide en cuatro rectángulos de $6 \times 4$ m por las medianas de los lados del rectángulo originario. El punto de intersección de las medianas, que se corresponden con los ejes de simetría axial del rectángulo, nos determina el punto central (figura 7, c). A su vez, podemos descomponer cada uno de los nuevos rectángulos en otros dos rectángulos de $3 \times 4 \mathrm{~m}$, formados por triángulos de $3 / 4 / 5 \mathrm{~m}$ (figura $7, \mathrm{~d}$ ).

En su interior podemos observar la presencia de cinco rectángulos de $3 \times 4 \mathrm{~m}$ (figura $7, \mathrm{~b}$ ). Tres de ellos, los situados al sur, asociados entre sí, conforman un rectángulo de $9 \times 4 \mathrm{~m}$, que se corresponde con el núcleo de la construcción; mientras que los otros dos podemos relacionarlos con las habitaciones situadas al norte.

Desde el punto de vista de su diseño, parece descomponerse en dos partes (figura 8, a y b), cada una generada con un sistema diferente. La occidental por 


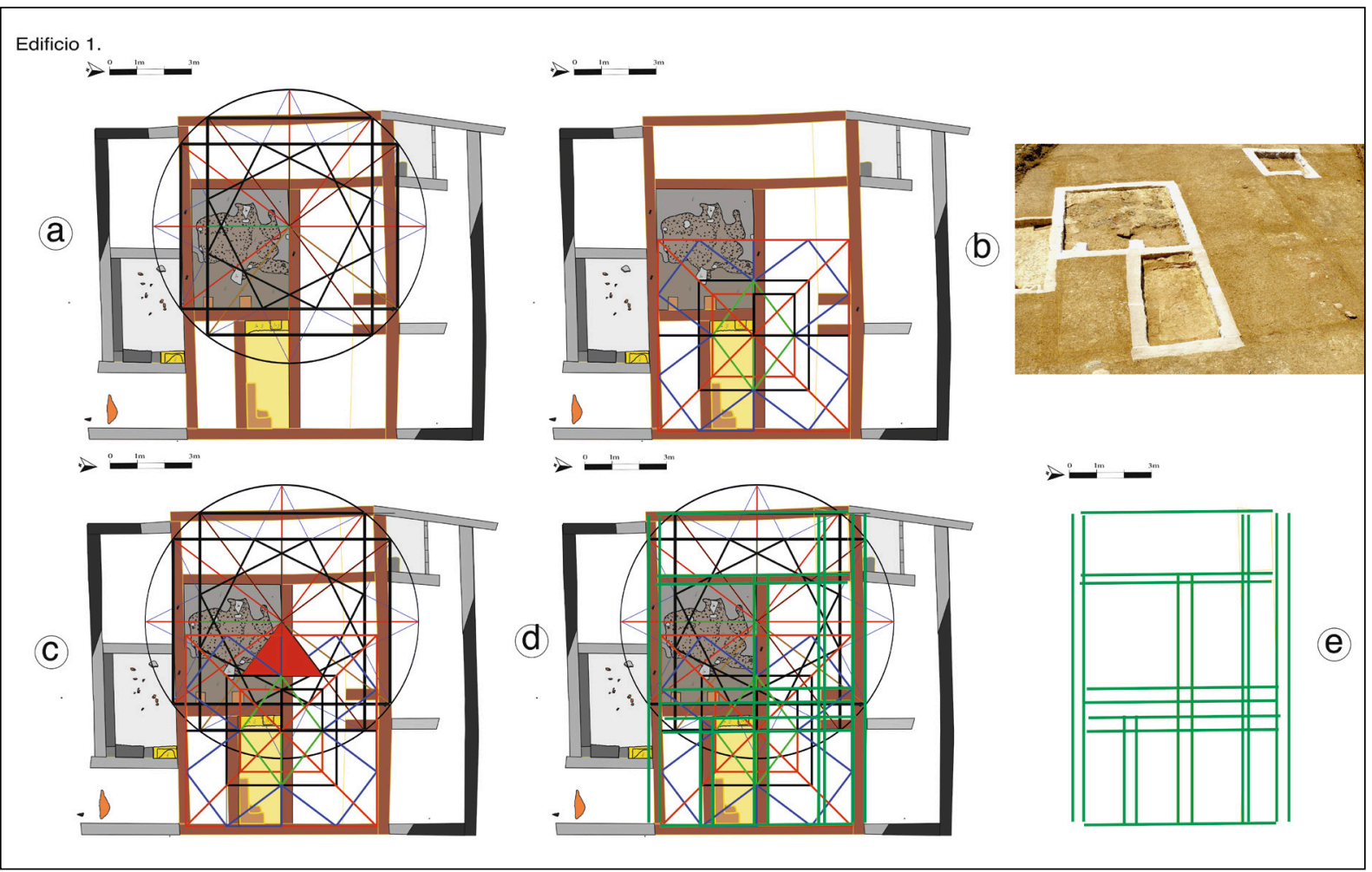

Figura 8. El diseño del Edificio 1 de La Rebanadilla

Figure 8. The design of E1 building of La Rebanadilla

medio de una estrella, y la oriental por medio de la figura en forma de aspa creada a partir del triangulo $3 / 4 / 5$ y sus cuadrados asociados. Lo más interesante es que los dos sistemas se complementan en la parte central de la construcción, aumentando el grado de detalle a la hora de situarse los elementos más significativos.

La relación de los dos sistemas no se hace de forma arbitraria, sino por medio de un triángulo rectángulo de $3 / 4 / 5$ codos, cuyo vértice del lado 4 con la hipotenusa se situaría sobre el punto central de la estrella, mientras que el vértice conformado por la unión de los catetos se posiciona sobre uno de los vértices del rombo localizado en el interior de la figura con forma de aspa (figura 8, c).

La estrella, a partir de los triángulos isósceles de $8 \mathrm{~m}$ de altura y base, se inscribe en el interior de una circunferencia de ro m de diámetro. Esta delimita los muros exteriores del edificio, así como la compartimentación interior. Destaca que, de nuevo, encontramos un elemento significativo: una de las piedras interpretadas como basa de uno de los pilares exentos del patio, situada de forma tangente a los lados de dos de los triángulos, en el punto en el que se cortan, enmarcada por las diagonales de los dos rectángulos construidos por las bases de los cuatro triángulos isósceles, significándose esta ubicación. La parte este, definida por la figura en forma de aspa, delimita la parte interior de los muros perimetrales, así como la ubicación del tabique existente entre las dos habitaciones traseras y la anchura de los elementos significativos adosados a ambas caras del muro que separa el patio de las habitaciones traseras. Vuelve a ser destacable que, nuevamente, este sistema remarca la ubicación del pilar del patio (figura 8, d).

En el estudio de esta construcción pudimos observar la presencia de un segundo nivel de diseño. De esta forma, en el patio vimos cómo encajaba, con su morfología, una estrella de la mitad de tamaño que la que se había utilizado para el diseño general, creada a partir de triángulos de $4 \mathrm{~m}$ de alto y base, correspondiente al que consideramos como módulo. Esta, además, volvía a resaltar la posición de la piedra del pilar exento, así como las pilastras adosadas al muro este (figura 9). 




Figura 9. Geometría del Patio del Edificio 1 de La Rebanadilla

Figure 9. Geometry of the yard of E1 building of La Rebanadilla

\subsection{Edificio 4}

El edificio denominado $\mathrm{E}_{4}$ (figura II, a) tiene orientación norte-sur. Se sitúa en la parte este del asentamiento, y presenta unas dimensiones máximas de, aproximadamente, $9,5 \times 9 \mathrm{~m}$, incluyéndose los muros exteriores. El área aproximada del $\mathrm{E}_{4}$ es de $85,5 \mathrm{~m}^{2}$, estando distribuido el espacio interior en once salas, compuesta por un templo y diez habitaciones auxiliares de diferentes tamaños. Tanto el edificio, de forma general, como alguno de sus muros interiores, se encuentran desalineados, presentando irregularidades en sus líneas.

El edificio se puede descomponer en dos volúmenes claramente diferenciados, uno al norte, de $9,5 \times 3 \mathrm{~m}$, compuesto por dos habitaciones, y otro al sur, de $6 \times 9 \mathrm{~m}$ que, a su vez, se puede dividir en otros tres bloques, dos en los laterales de $6 \times 4 \mathrm{~m}$, y uno central de I, $5 \times 6$ m (figura in, b). El volumen del lado oeste se corresponde con el Templo 1 de La Rebanadilla (figura I2), una única sala de planta rectangular, con orientación norte-sur. A los pies de la sala se localizan dos refuerzos o pilares adosados a su muro sur, de 0,35 × 0,40 m, localizándose entre medias de ellos un banco corrido/mesa auxiliar. La entrada corresponde a una pequeña abertura situada en la parte oeste del muro sur. En la cabecera, en una posición centrada, se encontró un adobe rectangular exento, que interpretamos como mesa/altar. Directamente al norte de este adobe, se localizó un agujero circular, que podría haber sido utilizado para la instalación de un betilo. Más o menos en el mismo eje, a media distancia entre la mesa/altar de la cabecera y el banco corrido/ mesa auxiliar de los pies, se situaba el hogar/altar, del cual solo queda la impronta, habiendo casi desaparecido con las diferentes reparaciones que se realizaron del piso al incorporar nuevas capas de revoco amarillo (Sánchez et alii, 2018: 308-309 y 2020: 245). La presencia de todos estos elementos sería una de las características que definen a los templos levantinos, según Edrey (2018: 185).

Lo más interesante de este espacio es que la parte interior de la sala, quitando las pilastras y la mesa/altar de los pies, corresponde a un rectángulo de $3 \times 4 \mathrm{~m}$. Por otro lado, los otros dos bloques conforman un conjunto de siete pequeñas habitaciones dispuestas en torno a un espacio central. Estas habitaciones se encontraban muy alteradas ya que, una vez se realizó el desmontaje ritual del complejo religioso, se excavó una estructura ovalada sobre los derrumbes que formaban el sellado de estas edificaciones, depositándose sobre ella los restos de un 


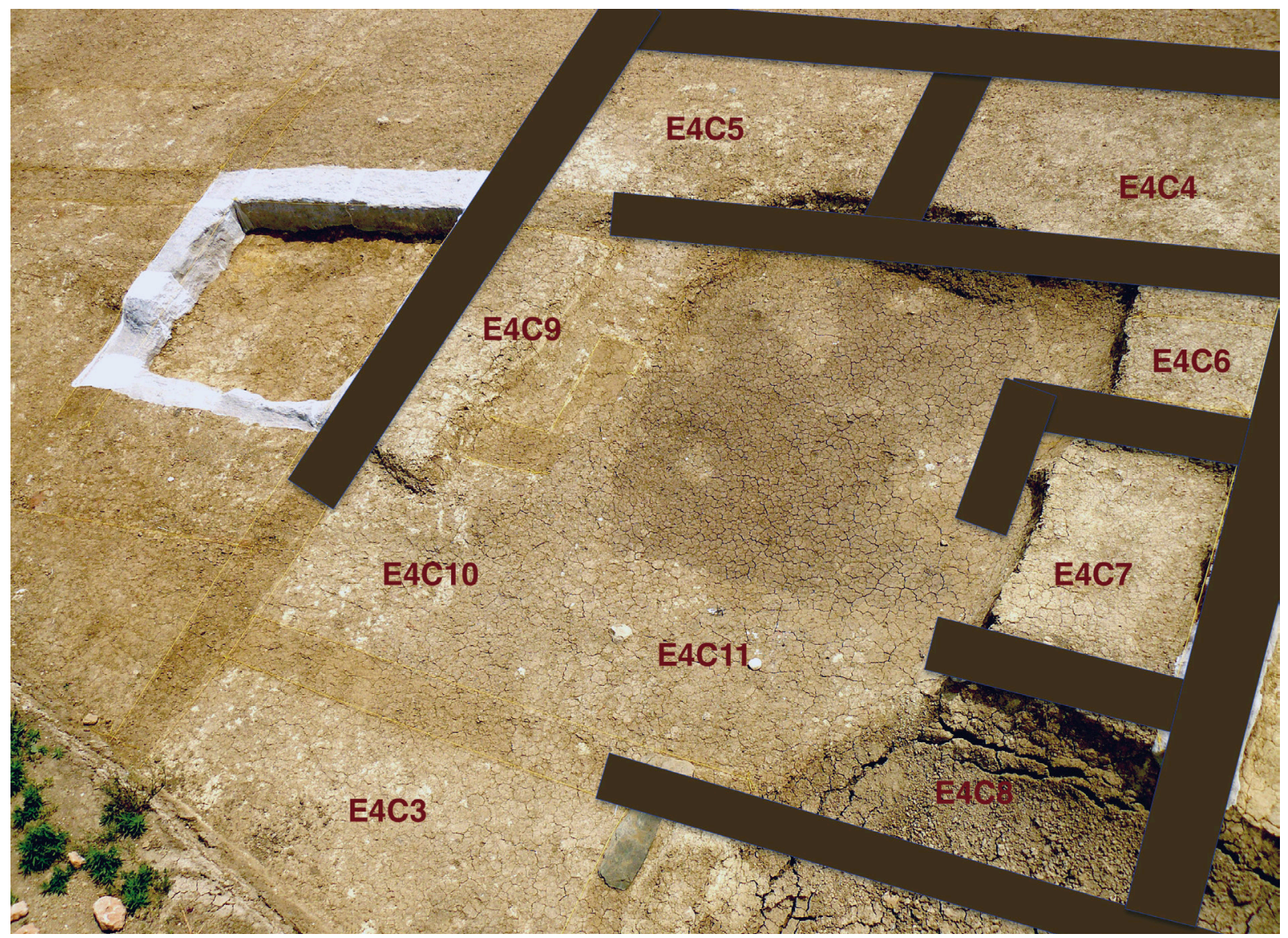

Figura 10. Recreación en planta de la parte oriental del edificio E4

Figure 10. Recreation on the ground floor of the eastern part of the E4 building

banquete colectivo, caracterizado por la documentación de vajilla para el consumo de vino - siendo este el último acto en el abandono ritual de los edificios religiosos de la Fase III de La Rebanadilla-. Esta estructura deformaba el conjunto habitacional, dificultando la apreciación de su morfología. Desde la estancia central se accedería a las habitaciones situadas al norte (figura ro).

La construcción del edificio se realiza mediante macizos de tierra, sin zócalo de piedra ni cimentaciones. Los muros se apoyan directamente sobre el sustrato geológico arcilloso, a excepción de la unión del muro medianero entre las dos habitaciones situadas al norte, con el que se separa el bloque norte del sur, y en donde se localizaron dos lajas de pizarra — de la misma dimensión que los muros- reforzando el asiento de estos y la unión entre ellos (figura II, a).

Las paredes y suelos de las estancias se encuentran revocadas con lechadas arcillosas amarillas, de composición similar a la de los adobes/macizos de tierra. Las entradas a las diferentes estancias se sitúan siempre en las esquinas, presentando la puerta al Templo 1 varios peldaños para sortear el umbral, que se encuentra elevado con respecto al suelo de las estancias.

Tipológicamente se puede descomponer en dos partes por su volumen arquitectónico y por su uso. La parte oriental, que es similar, en su morfología, a la del banquete, correspondería a un templo de una sola nave. Este espacio sagrado tiene paralelos orientales, desde el II milenio, en el Templo Menor de Khafadje (Margueron, I99r: I23r; Fernández y Rodríguez, 2007: 217, fig. 90), y en el Templo de Baal y Astarté de Tell Mevorak (Perra, I998: I85; Fernández y Rodríguez, 2007: 217, fig. 91); y en el primer milenio, en el Templo de Astarté de Sarafand (Wright, 1985: fig. 165; Perra, 1998: 129; Fernández y Rodríguez, 2007: 217, fig. 92). La parte occidental estaría compuesta por un rectángulo principal en donde una habitación central da acceso a un conjunto de pequeños almacenes. Por último, el conjunto estaría 


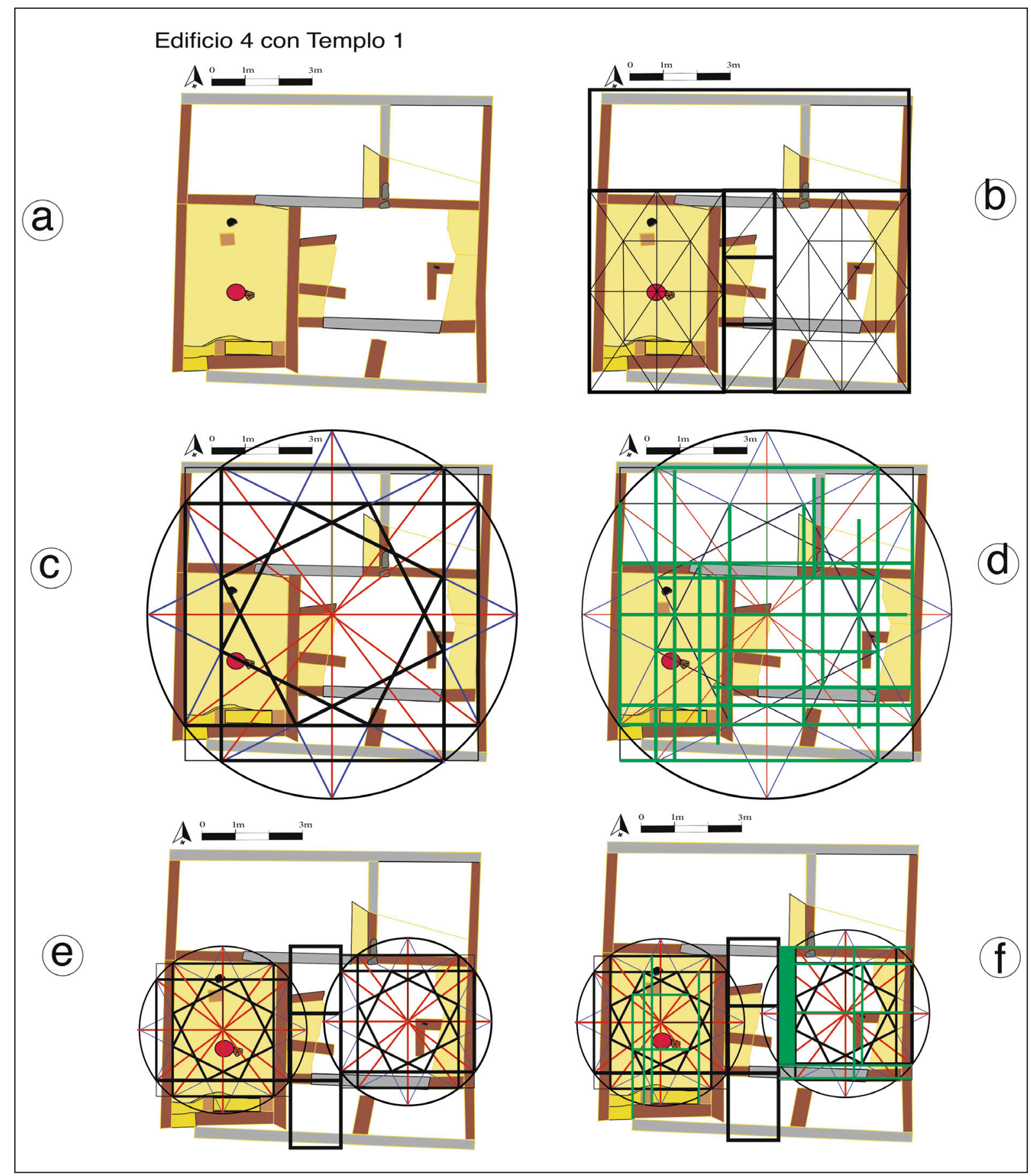

Figura 11. El diseño del Edificio 4 de La Rebanadilla

Figure 11. The design of E4 building of La Rebanadilla

cerrado por el norte por dos habitaciones que podrían ser auxiliares del templo, y a las que se accedería desde el bloque occidental.

La construcción del $\mathrm{E}_{4}$ se diseña en torno a una estrella formada por los triángulos isósceles (figura II, c), del tamaño del módulo por 2+I/Io, equivalente a una estrella inscrita en un circulo de II $\mathrm{m}$ de diámetro. Por medio de ella se definen los límites interiores de la construcción, así como las distribuciones interiores principales. La mesa/altar del Templo 1 vuelve a estar tangente a dos ejes principales de la construcción, en el punto en donde se cortan estas dos líneas, el eje de simetría este-oeste y la base del triángulo orientado al este, enmarcándolo. 


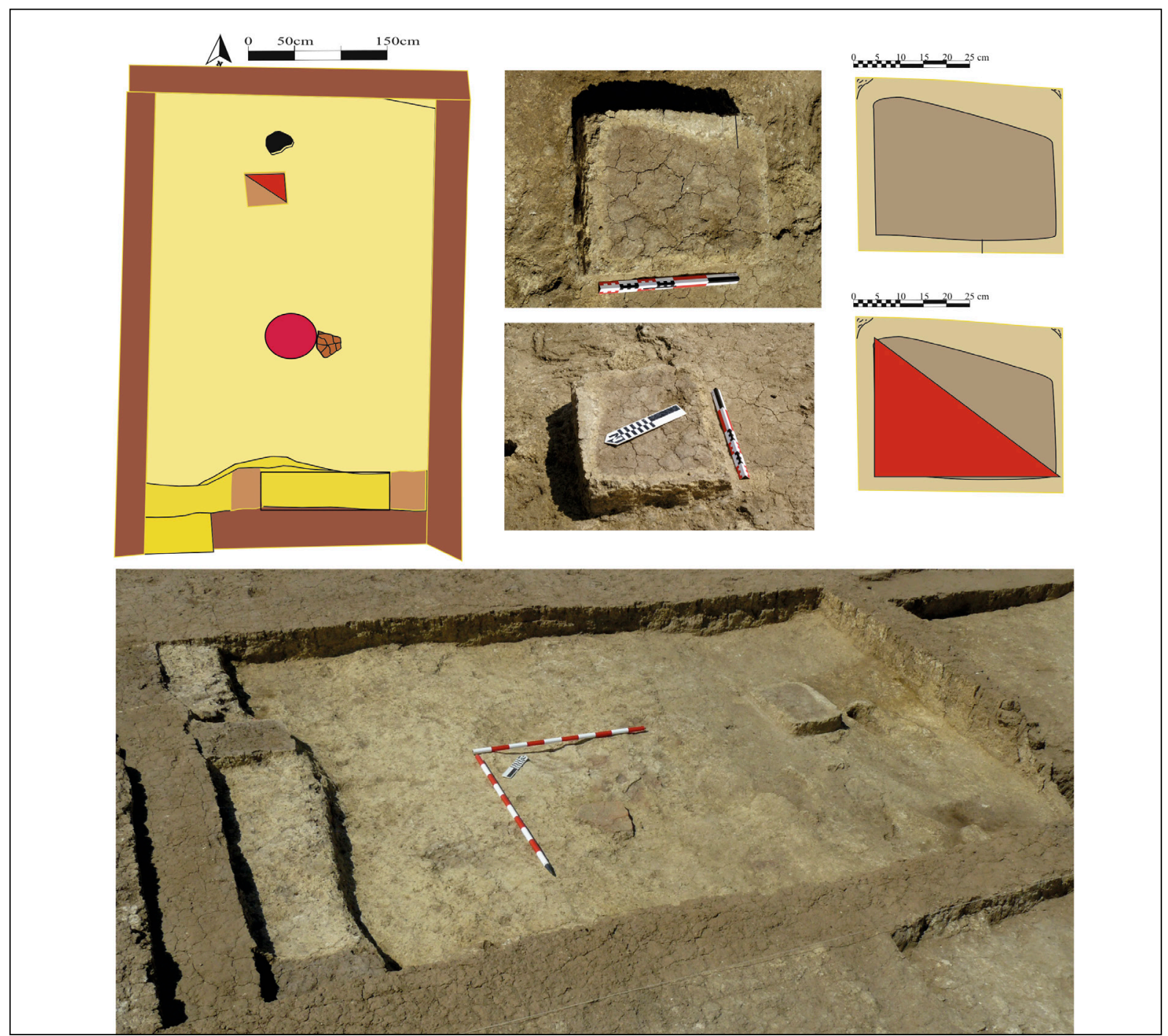

Figura 12. El triángulo $3 / 4 / 5$ y el Altar/Mesa del Templo 1

Figure 12. The $3 / 4 / 5$ triangle and the Altar / Table of Temple 1

Existe un segundo nivel de detalle que define con mayor claridad los espacios principales de la parte sur del edificio. Este segundo nivel deriva de la utilización de la estrella de tamaño base, construida mediante un triángulo rectángulo de $3 / 4 / 5$ codos, para definir las principales características del conjunto de almacenes auxiliares situados al este, distribución de las salas, anchura de los muros y ubicación de las puertas; y del Templo 1, ubicación de los muros en su cara interior, anchura de los muros laterales y localización de la puerta de acceso (figura II, e). Se delimitan las pilastras adosadas al muro sur, así como la mesa auxiliar situada entre medias de estas. El hogar/altar queda inscrito en el interior de un triángulo, conformado por las diagonales del rectángulo formado por las bases de los dos triángulos situados en el eje norte-sur. El agujero para la ubicación del betilo es tangente al eje principal norte-sur, al igual que la mesa/altar principal que vuelve a encontrarse delimitada, tangencialmente, por ejes secundarios, posicionándose el ángulo noreste del altar sobre el punto donde se cortan los dos triángulos situados en el eje este-oeste y el eje principal (figura II, f).

La mesa/altar principal, compuesta por una parte central de color marrón sobre la que se ha añadido un grueso enlucido de color amarillento, tiene unas dimensiones de $0,35 \times 0,46 \mathrm{~m}$, siendo la parte interior de, aproximadamente, $0,30 \times 0,40 \mathrm{~m}$; por lo que podría haberse formado a partir de un triángulo $3 / 4 / 5$ (figura I2). 


\subsection{Edificio 5 o Templo 2}

El edificio denominado como $\mathrm{E}_{5}$ o Templo 2 (figura I3, a), se encuentra situado en la parte noroeste de La Rebanadilla, con una orientación norte-sur. Sus dimensiones generales son $6 \times 4,5 \mathrm{~m}$, equivalente a $27 \mathrm{~m}^{2}$. Está compuesto por un patio, situado en la parte norte, $y$ dos habitaciones traseras de pequeño tamaño (Sánchez et alii, 2018: 309-310 y 2020: 245-246). El patio, de forma trapezoidal, está ligeramente deformado con respecto a las habitaciones. En él se localizan dos altares/hogares; el primero, que ocupa una posición central en el edificio, originariamente fue de los denominados de «piel de toro», reformándose en un segundo momento, pasando a ser rectangular, de 0,28 × 0,38 m (Sánchez et alii, 2020: 246); el segundo, situado en la parte noroeste del patio, tendría forma circular, estando bastante perdido por las diferentes reparaciones del pavimento. También forma parte del mobiliario de este espacio una mesa/altar, adosada a la pared medianera con la sala sureste, identificada con el sanctasanctórum o espacio en donde residiría la divinidad (Sánchez et alii, 20I8: 3IO-3II y 2020: 246). En ella se podrían dejar las ofrendas sin necesidad de pasar hasta el interior del templo, lo que nos indicaría que no todo el mundo tiene acceso hasta el espacio más sagrado del mismo - como ocurre con el grupo de templos orientales con lateral bent-entry (Edrey, 20r8)-, y que existe un mecanismo para la realización de las ofrendas sin tener que acceder a la zona más sagrada. La parte meridional está compuesta por dos salas situadas en paralelo. Desde el patio se accedería a la estancia suroeste y, desde esta, se ingresaría en la del sureste por medio de un vano en la parte sur del muro que separa estas dos salas, localizándose en esta un betilo y una piscina/hogar rehundido, correspondiendo, como decíamos, al espacio más sagrado de la edificación.

Volumétricamente se compone de dos partes aparentemente iguales: la septentrional o patio, y la meridional con dos habitaciones. La construcción se realiza mediante macizos de tierra, sin zócalo de piedra ni cimentaciones, donde los muros se apoyan directamente sobre el sustrato geológico arcilloso. Estos tienen una anchura media de $0,45 \mathrm{~m}$, siendo mucho más anchos los laterales del patio que los del resto de la construcción, llegando a alcanzar los o,67 m. Las paredes y los suelos se encuentran revocados con lechadas amarillas de arcillas, de composición similar a la de los adobes/macizos de tierra que, en parte, se encuentran perdidas en el patio, dejando a la vista un preparado a base de pequeños cantos de río. La entrada al sanctasanctórum tenía un suelo diferencial realizado con pequeñas gravas a modo de alfombra. En el interior se documentan altares/hogares, bancos corridos y altares/mesas auxiliares realizados con las mismas técnicas constructivas. Las puertas corresponden a pequeños vanos abiertos en las esquinas de los muros, de no más de o,70 m.

El edificio $\mathrm{E}_{5}$ tiene como característica las numerosas irregularidades y desalineaciones que presentan sus muros. En las habitaciones situadas en la parte sur, los ángulos rectos de las habitaciones se convierten en agudos en las esquinas noroccidentales y surorientales, mientras que las nororientales y suroccidentales suelen presentar ángulos obtusos. E1 patio también se aleja del diseño original regular, con grandes desalineaciones e irregularidades, en especial en la esquina noreste y muro oriental, como si la pared se hubiera ido desgastando, ganándole tamaño el interior del patio.

Los paralelos en la península ibérica los encontramos en El Carambolo V (Fernández y Rodríguez, 2007: 93-104); y, en Oriente, en los templos de Tell Taya o Tell el-Ghasshil (Fernández y Rodríguez, 2007: 219-220; Díes Cusí, 200I: 78), y en el «Edificio del Patio con Pilares en el Área N» de Tel Kinrot (Nissinen y Münger, 2009).

La planta de este templo acepta los dos modelos básicos de diseño, el conformado por la estrella (figura $\mathrm{I}_{3}, \mathrm{~d}$ ) del doble de tamaño de la identificada como módulo, y el generado a partir del polígono con forma de aspa (figura I3, b). De hecho, el modelo responde mejor cuando se combinan ambos con un mismo centro (figura I3, e). La estrella nos define los límites exteriores de los muros laterales e interiores de los muros norte y sur. Los dos ejes de simetría principales, compartidos con el modelo en aspa, generan los volúmenes ideales de los tres espacios. La puerta entre las dos habitaciones traseras queda definida por el punto en el que se cortan los dos triángulos situados en el eje este-oeste. El punto en el que 


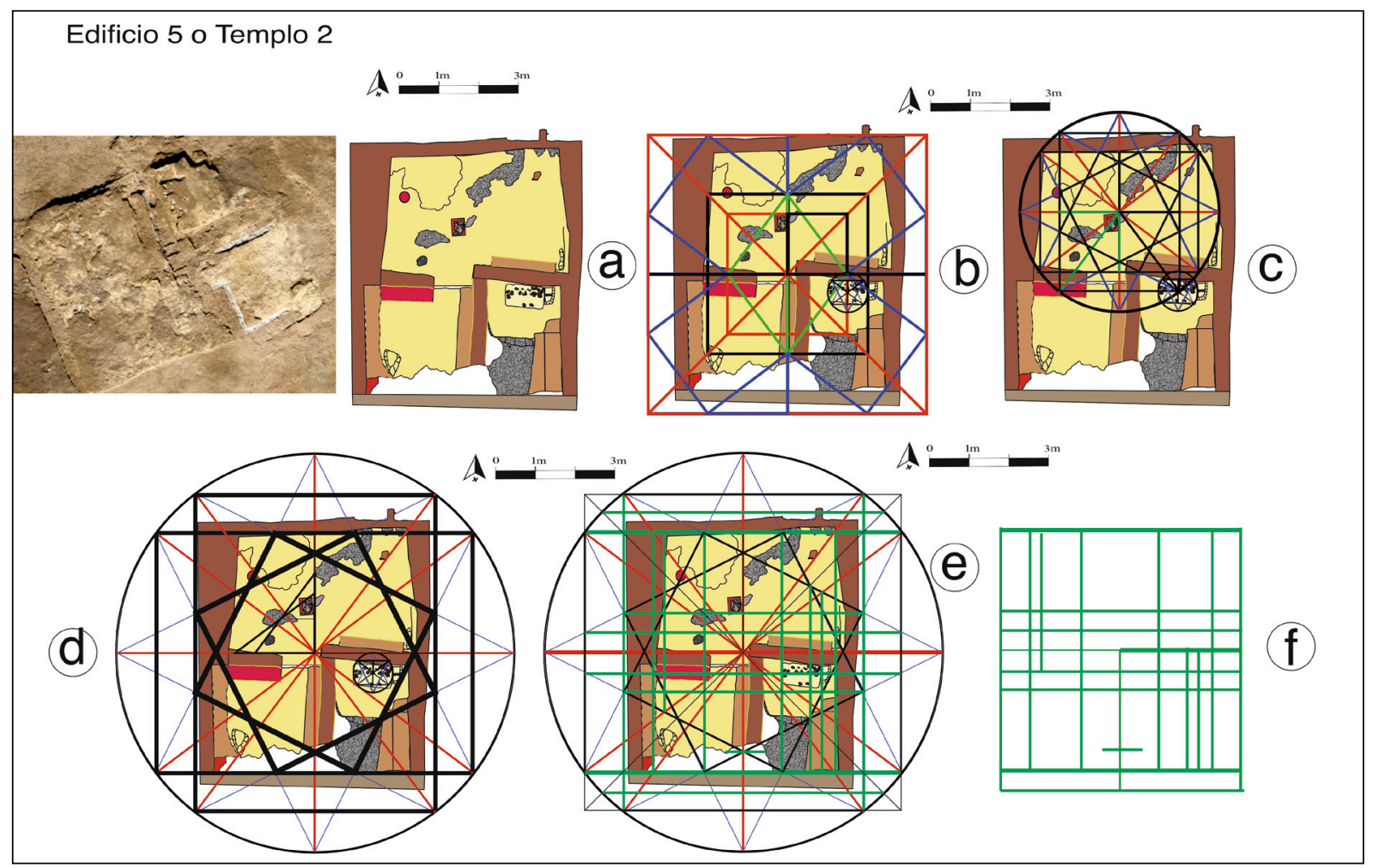

Figura 13. El diseño del Templo 2 de La Rebanadilla

Figure 13. The design of Temple 2 of La Rebanadilla

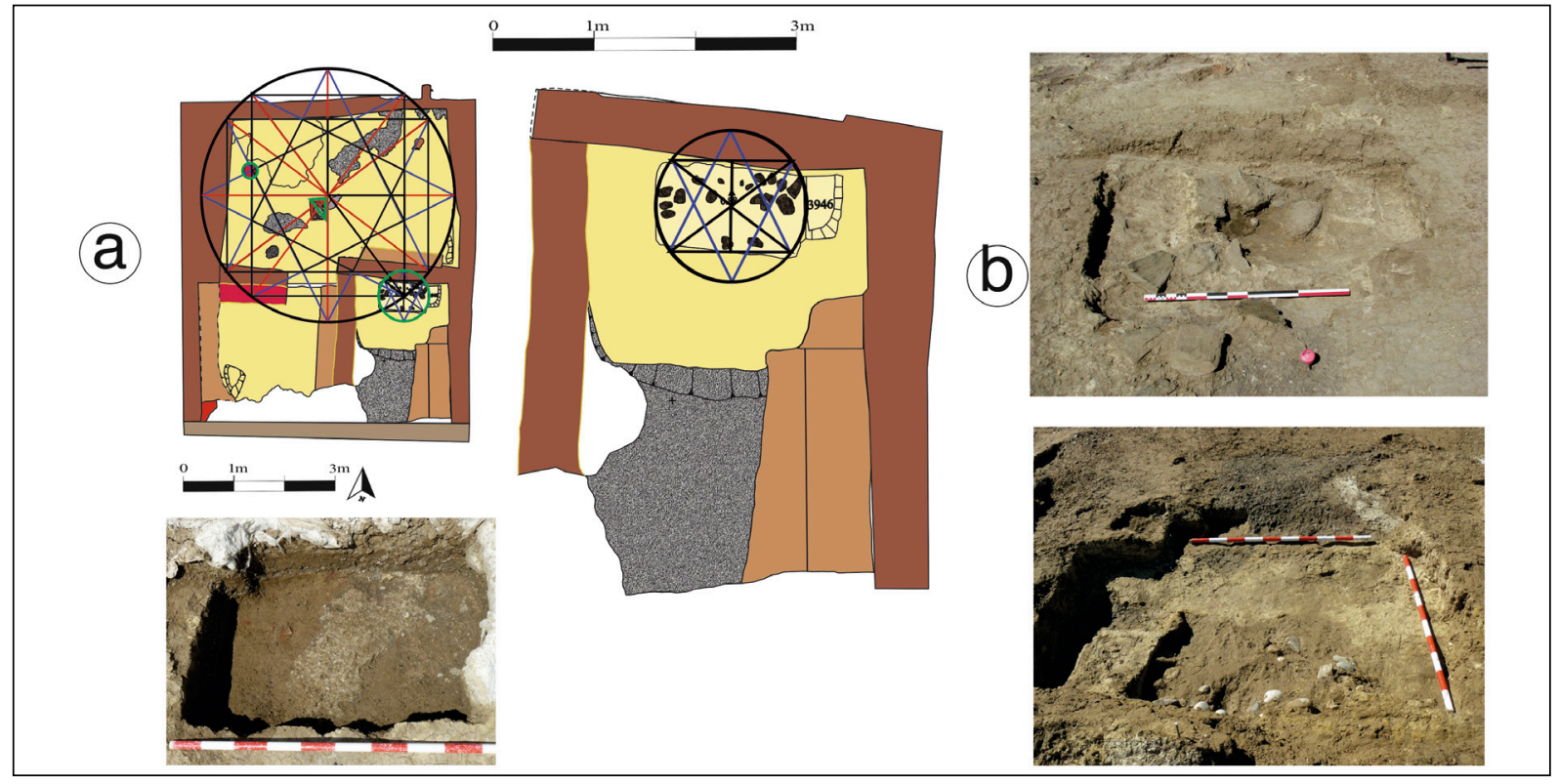

Figura 14. La relación del triángulo isósceles y el Altar/Hogar/Piscina del Templo 2 de La Rebanadilla

Figure 14. The relationship of the isosceles triangle and the Altar / hearth / Pool of Temple 2 of La Rebanadilla

se corta el triángulo que apunta al sur con el que lo hace hacia el este, determina el límite entre el espacio correspondiente al sanctasanctórum y el suelo de gravas grises. El hogar/altar de "piel de toro», situado en el patio, es tangente al eje de simetría norte-sur; y el hogar circular se sitúa en el punto en donde se corta el triángulo que apunta al norte con el que lo hace hacia el oeste. Mientras, la figura en forma de aspa nos define la ubicación de los bancos corridos de las dos salas, el límite interior del patio, nuevamente el límite 


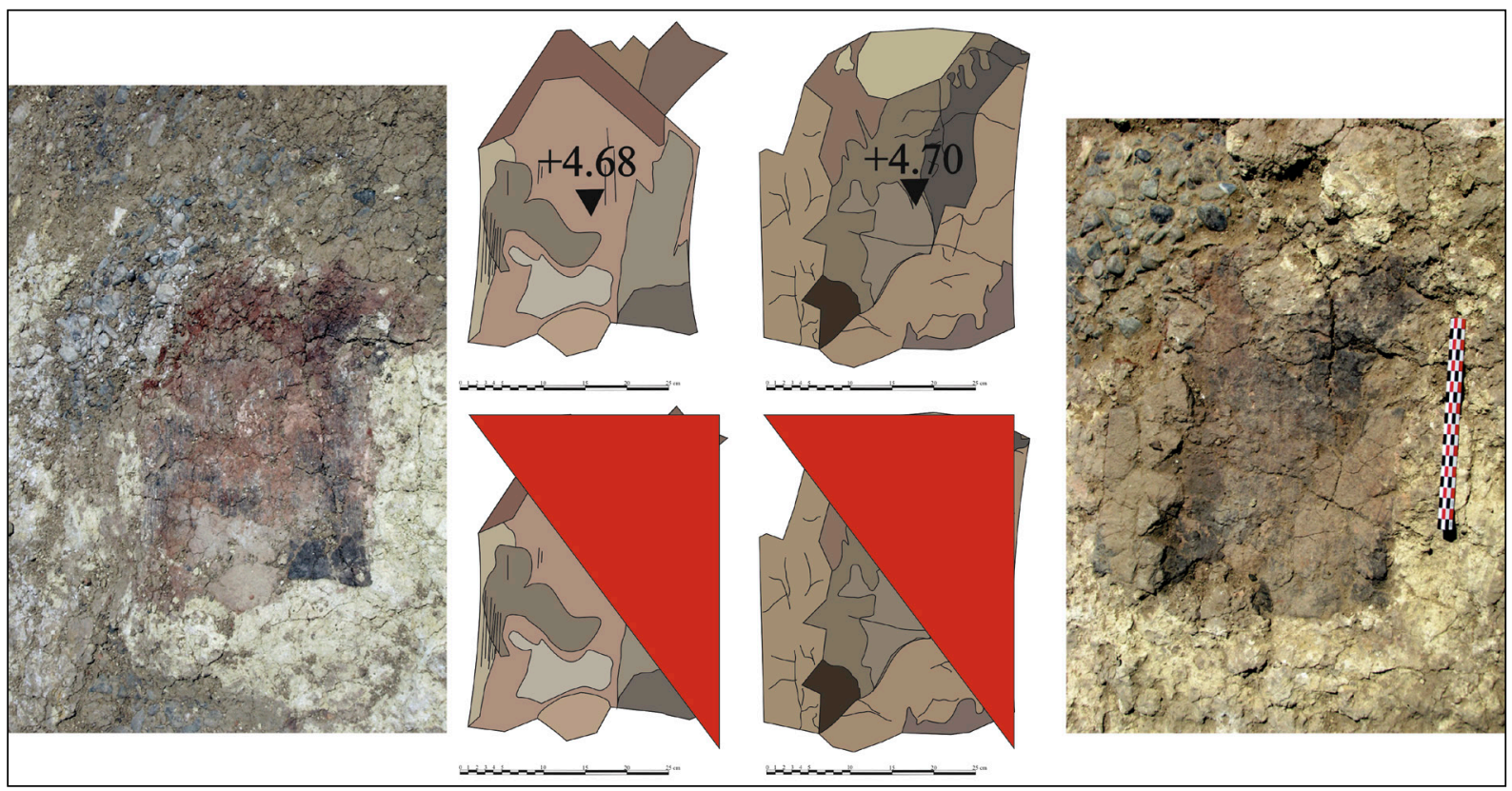

Figura 15. El triángulo 3/4/5 y el Altar/Hogar del Templo 2

Figure 15. The $3 / 4 / 5$ triangle and the Altar / Hearth of Temple 2

entre el sanctasanctórum y el suelo de gravas grises, y la ubicación de la mayoría de los altares u hogares. El hogar/altar de «piel de toro» queda enmarcado por el ángulo interno del cuadrado de $3 \times 3$ codos situado en el cuarterón del noroeste, mientras que la piscina/hogar rehundido quedaría tangente a su límite este, con el cuadrado de 4 codos situado en el sureste. Esta podemos delimitarla por medio de una estrella cinco veces mas pequeña que el módulo, situándose el vértice superior del triángulo que apunta al norte sobre el vértice este del rombo interior de la figura con forma de aspa, rombo conformado por medio de cuatro triángulos $3 / 4 / 5$.

Sobre este edificio también podemos aplicar un segundo nivel de detalle por medio de una estrella, de tamaño igual al módulo, situada en el punto central del patio (figura I4, a), quedando mejor delimitado el contorno interior de este espacio. Se vuelve a atestiguar cómo los elementos más significativos, como son el hogar circular, el hogar/altar de "piel de toro» del patio y la piscina/hogar rehundido del sanctasanctórum, ocupan espacios destacados del diseño. Este hogar/altar queda enmarcado por los dos ejes de simetría principales en su unión en el punto central de la figura; y el hogar circular por el punto en el que se cortan los triángulos orientados hacía el norte, sur y oeste, y el circuncentro de la circunferencia en el que se inscribe la estrella que delimita la piscina/hogar en el vértice sureste del rectángulo conformado por los dos triángulos situados en el eje norte-sur (figura I4, b).

Igual que nos ocurría con la mesa/altar del Templo 1, en el interior del hogar/altar del patio del Templo 2 podemos inscribir un triángulo recto $3 / 4 / 5$, de $0,30 \times 0,40 \times 0,50 \mathrm{~m}$ (figura 15 ).

\section{Otro ejemplo peninsular. El Carambolo V}

Como muestra de control, hemos repetido estos mismos planteamientos sobre otro edificio significativo y coetáneo de la península ibérica, el Templo de El Carambolo V (Fernández y Rodríguez, 2007: 93-Io9) a través de la planta publicada por sus excavadores (Fernández y Rodríguez, 2007: fig. 8). En esta planta (figura I6, a), al igual que en las fotos aéreas de la publicación (Fernández y Rodríguez, 2007: figs. 5 y 2I), era visible, en la rampa de acceso, un triángulo isósceles. El análisis de este, representado en la planimetría, nos deparó que fue construido a partir de un triángulo rectángulo del grupo $3 / 4 / 5$. Como los 


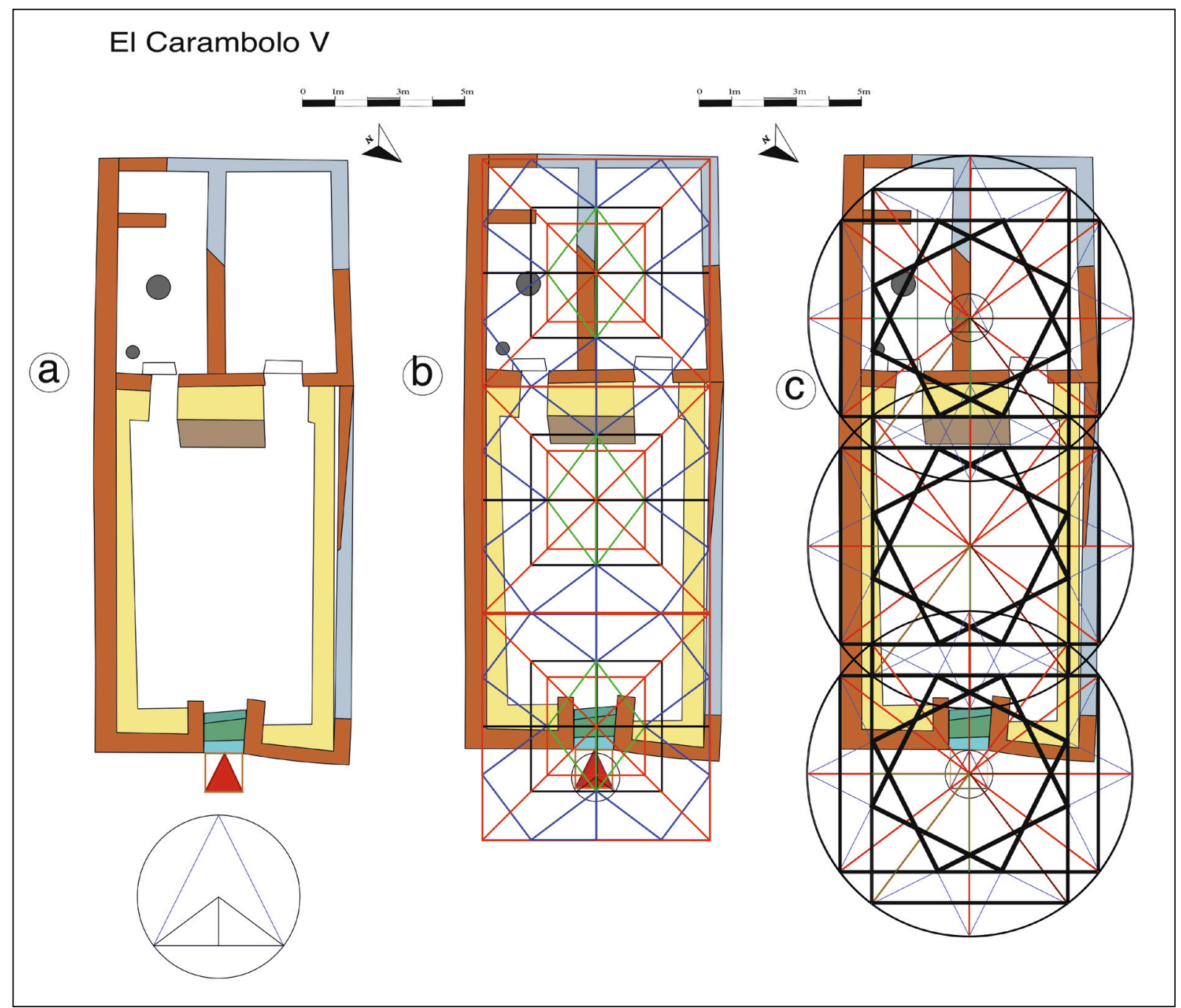

Figura 16. El diseño del Carambolo V

Figure 16. The design of Carambolo $\mathrm{V}$

maestros constructores medievales que grababan los módulos de su diseño en sus edificios, los constructores fenicios pareciera que nos hubieran dejado el módulo de esta construcción.

Este triángulo, cercano a I,I4 $\mathrm{m}$ de base y altura, sería el resultado de dividir entre siete los triángulos isósceles de $8 \mathrm{~m}$ de base $\times 8 \mathrm{~m}$ de altura con los que se realiza la estrella utilizada para el diseño del edificio, la que multiplica por dos el módulo y que podemos inscribir en un círculo de ro $\mathrm{m}$.

El diseño de El Carambolo V se crea a partir del circuncentro del triángulo situado en la entrada. Sobre él se posiciona, compartiéndolo, la primera estrella, con la que se dibujan los límites exteriores laterales del edificio, así como la entrada y su escalera (figura i6, c).
A continuación de la primera, se coloca una segunda estrella. Esta se sobre-escribe parcialmente sobre la primera, relacionándose con esta mediante el circulo que la inscribe, al atravesar los puntos en donde se cortan los dos rectángulos que dibujan los triángulos isósceles de la primera. Esta estrella dibuja los límites interiores del patio, sin su mobiliario, y define la ubicación de la mesa/altar, situada adosada al muro este del patio, el que hace de medianero con las habitaciones traseras, así como los límites exteriores de la construcción.

Por último se coloca, sobre esta segunda estre1la, una tercera con los mismos condicionantes: las circunferencias cortan los puntos en donde se unen los rectángulos de la otra. Esta continúa definiendo los límites exteriores de la edificación, así como el 


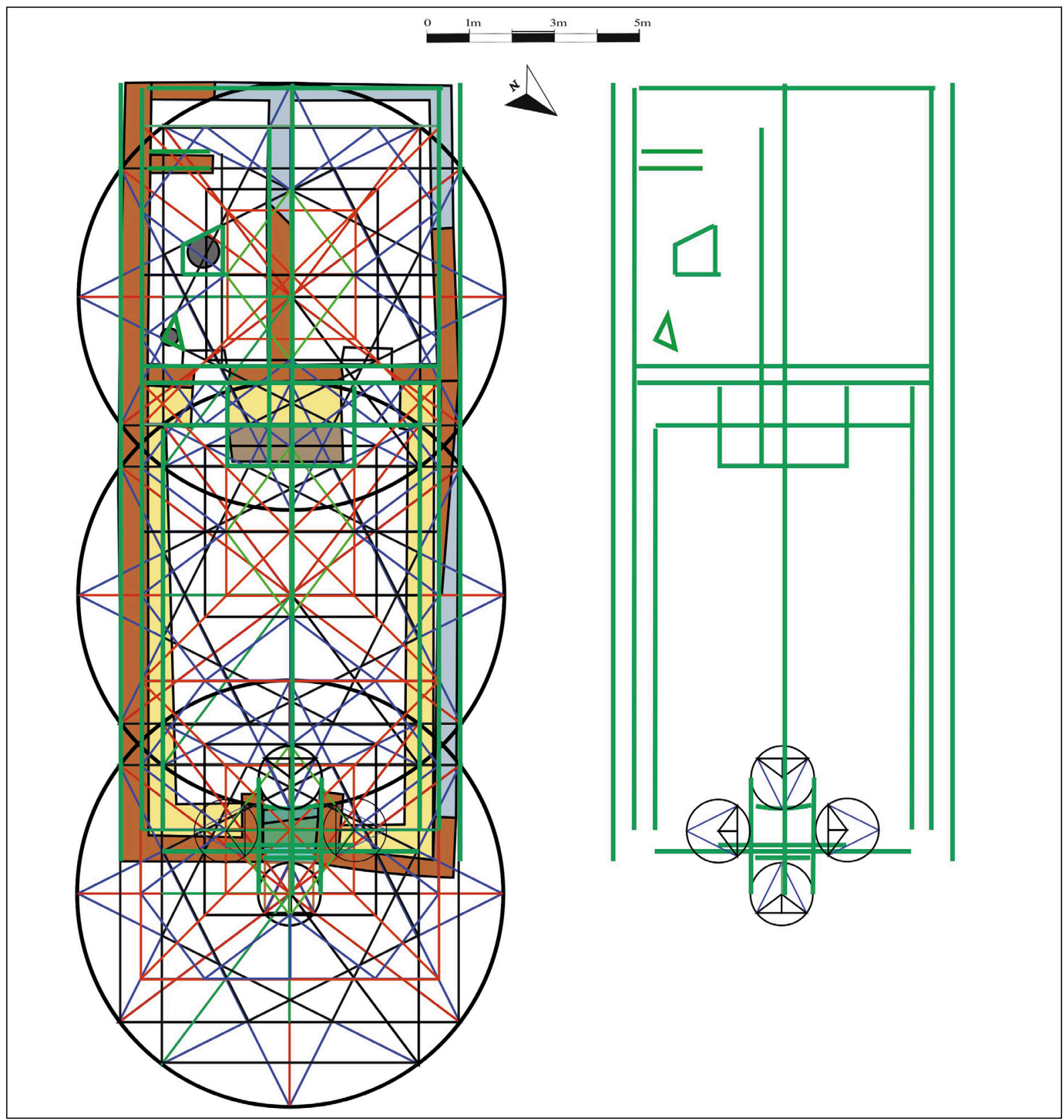

Figura 17. La unión de los modelos sobre la planimetría del Carambolo V

Figure 17. The union of the models on the planimetry of Carambolo $\mathrm{V}$

volumen, distribución de los espacios de las dos habitaciones traseras y ubicación de las puertas. Como ocurría en La Rebanadilla, los altares y hogares vuelven a encontrarse delimitados de forma tangencial por los lados de los triángulos isósceles en su punto de corte con otro.

Este diseño parece volver a completarse con la figura en forma de aspa (figura i6, b), como ocurría con el Templo 2 de La Rebanadilla. Estos dos edificios corresponden a una misma tipología de templo, compuesto por un patio que da acceso a las habitaciones traseras, en donde residiría la divinidad. Tienen también en común, la presencia de una mesa/altar en el patio, en donde poder colocar las ofrendas a la divinidad sin necesidad de pasar al interior de la sala, por lo que los dos deberían de compartir el hecho de que no todo el mundo puede entrar a esos espacios, quedando reservados para los sacerdotes, aunque un mayor número de personas podrían realizar sus ofrendas desde el patio. 


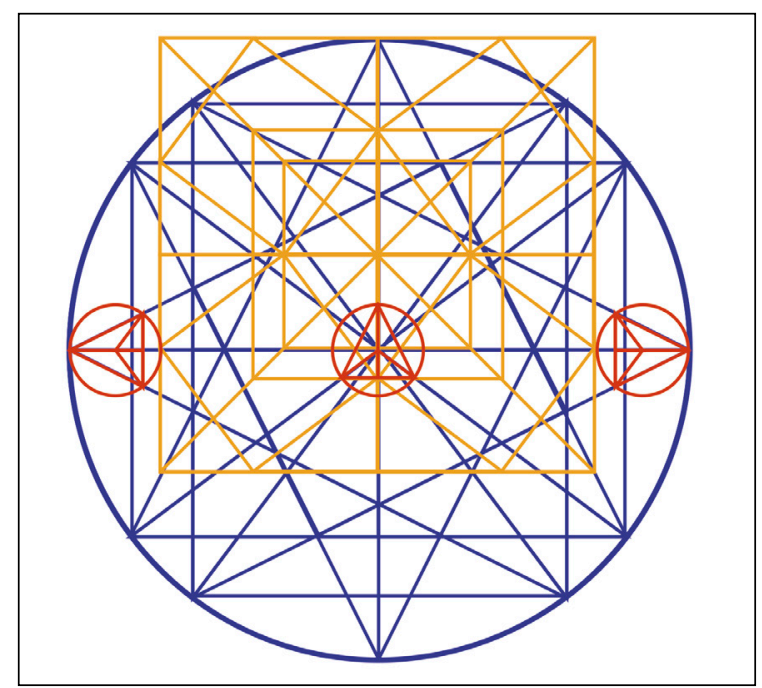

Figura 18. Relación entre las formas estrella y aspa utilizadas en el Carambolo V

Figure 18. Relationship between the star and cross shapes used in Carambolo V

Igual que con las estrellas, se combinan tres figuras en forma de aspa. La primera se posiciona colocando el vértice oriental del rombo, situado en su interior, sobre la base del triángulo isósceles de la entrada en su unión con la mediana del vértice superior o eje de simetría principal. La segunda se posiciona a continuación, pegada a la primera. De igual forma ocurre con la tercera, que se sitúa a continuación de la segunda, produciéndose una sucesión de rombos formados por triángulos 3/4/5 que van variado su orientación.

Estas figuras definen los límites interiores de los muros laterales, el paramento oriental y occidental del edificio, la ubicación del muro que separa las habitaciones traseras del patio, la luz y posición de las puertas que comunican estos espacios, la distribución espacial interior de las habitaciones traseras, y alguno de los elementos de la entrada al edificio. Los hogares y altares de la habitación situada al suroeste están en posiciones remarcadas. El altar circular es tangente al eje norte-sur de la figura colocada más hacia el oeste, estando su centro próximo al punto en donde se cortan el cuadrado de 5 de lado y el de 4 del cuarterón sureste de esta figura. El hogar es cortado por uno de los lados del cuadrado de 5 de lado, cerca de la diagonal sureste-noroeste de los cuadrados (figura I7).

Las dos figuras se relacionan entre sí compartiendo el eje de simetría principal este-oeste. El segundo eje de simetría de la estrella se coloca encima de los lados orientales de los cuadrados de 4 de lado, y el cuadrado en el que se inscribe la figura con forma de aspa es tangente a la circunferencia en la que se inscribe la estrella, en su lado occidental. E1 triángulo isósceles situado en la entrada del edificio sirve para soldar las dos figuras. Además de la posición de las dos figuras con respecto a su base y su circuncentro, que hemos comentado anteriormente, la circunferencia de esta figura se corresponde con la distancia que hay entre la circunferencia que inscribe la estrella y el cuadrado exterior de la figura con forma de aspa, en el eje norte-sur (figura r8).

\section{El diseño de los edificios en el Mediterráneo Oriental}

Del mismo modo que hemos planteado los edificios de la península ibérica, repetimos el estudio sobre las planimetrías publicadas pertenecientes a otros edificios significativos del Mediterráneo Oriental.

\subsection{El Templo de Astarté de Kition}

Para el estudio de este edificio se ha utilizado como base la planta de Karageorghis (I976: fig. I8) del Piso 3, correspondiente a la primera construcción fechada en el siglo Ix a. C., que utilizó como cimientos un templo anterior de la Edad del Bronce. La construcción estaba orientada en el eje este-oeste, ubicándose su área sagrada en la parte occidental, sobre una estructura elevada I $\mathrm{m}$ sobre el nivel del piso, a la que se accedía por tres escaleras. Delante de esta estructura se situaban dos pilastras rectangulares de piedra. A casi $3 \mathrm{~m}$, hacia el este de la pilastra sur, se disponía una mesa de ofrendas, consistente en una losa rectangular. En la sala principal se documentan cuatro filas de siete basas de columna con orificio para la introducción de un poste de madera (Edrey, 2018: 193).

La entrada se situaba en el extremo este del muro sur (Edrey, 20I8: 193; Karageorghis, I976: 96-IoI). Esta entrada, posicionada en un lateral, permite a Edrey integrar esta edificación en su grupo de templos con lateral bent-entry (20I8). Estas entradas tendrían la función de garantizar la protección de las 


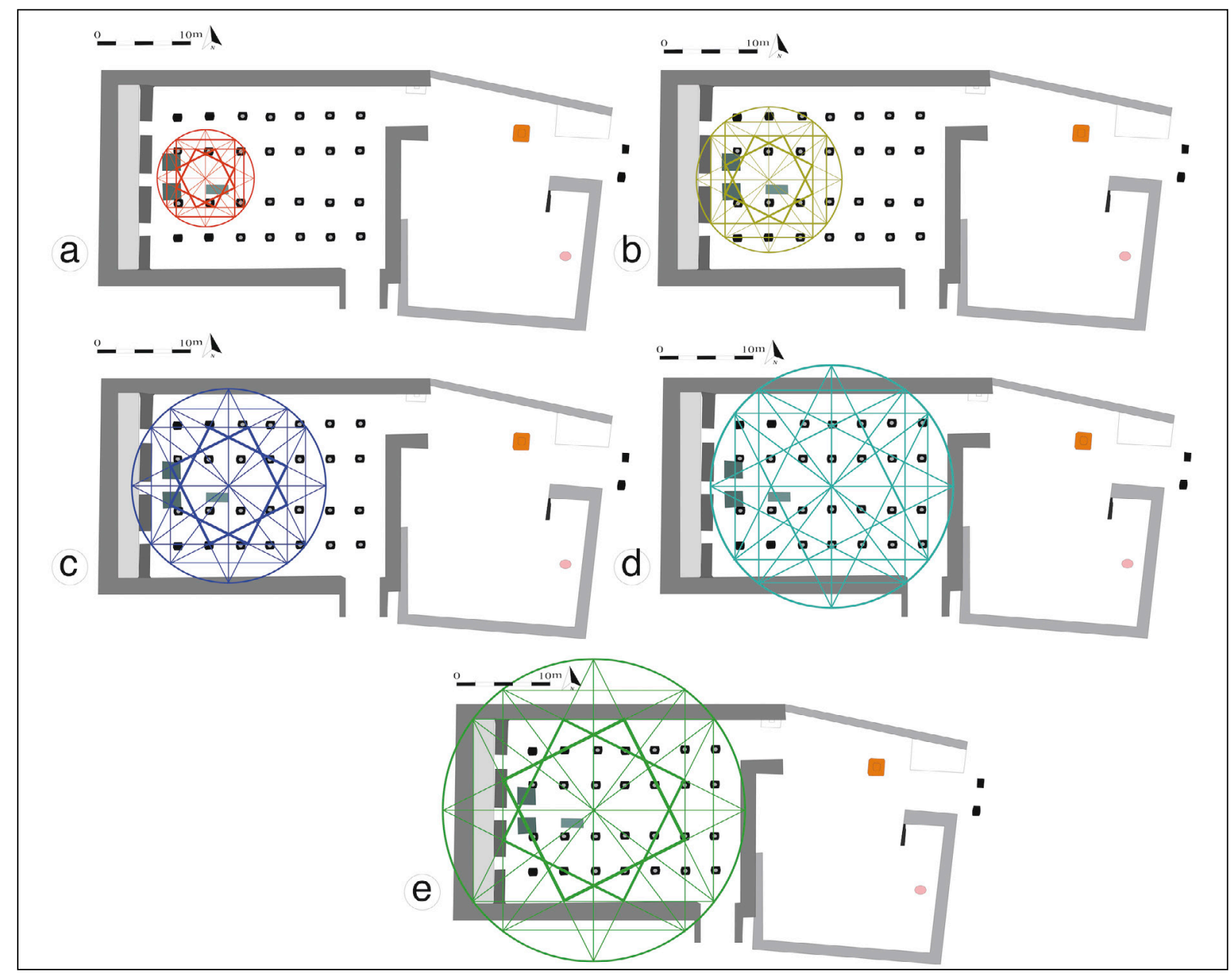

Figura 19. El codo de $52 \mathrm{~cm}$ en el templo de Astarté de Kition

Figure 19. The $52 \mathrm{~cm}$ cubit in the temple of Astarte of Kition

actividades realizadas en su interior frente al mundo exterior, ya que estarían reservadas solo a los sacerdotes (Edrey, 2018: 198-199).

En este edificio observamos la posible utilización de diferentes módulos para el codo, en función de cómo se ajusta el diseño a los diferentes elementos que conforman la construcción. Igualmente, se observan diferentes niveles en el diseño. Exclusivamente, el diseño encaja con la figura en forma de estrella.

Los elementos atestiguados en la parte interior de la construcción se ubicaban mejor utilizando un codo de $\mathrm{o}, 52 \mathrm{~m}$ para definir las figuras, mientras que el volumen de la edificación se ajusta mejor a un codo de o,50 m.

La estrella, de tamaño dos veces el módulo, construido con un codo de $\circ, 52 \mathrm{~m}$, define un núcleo ritual en donde se sitúan los elementos más importantes de la sala principal, delimitado por las dos pilastras localizadas delante del área sagrada, y por las tres primeras basas de las dos filas centrales. La mesa de ofrendas se coloca en el ángulo sureste conformado por los ejes de simetría de la estrella, siendo tangente al eje sur (figura I9, a).

La forma de estrella de tamaños 3 (figura I9, b), 4 (figura I9, c) y 5 (figura I9, d) veces la del módulo, igualmente utilizando el codo de o,52 m, definen la posición de las basas de la sala principal, si bien la ubicación del centro de las estrellas se va moviendo por el eje este-oeste.

Los tres accesos a la plataforma elevada, donde se sitúa el área sagrada, quedan perfectamente delimitados por las estrellas de tamaño 3 (figura 19, b) y 4 (figura I9, c).

El espacio interior del edificio se delimita por una estrella seis veces el tamaño del módulo, construida con un codo de $0,54 \mathrm{~m}$ (figura 19, e). Estos cambios en el tamaño del codo también parecen 


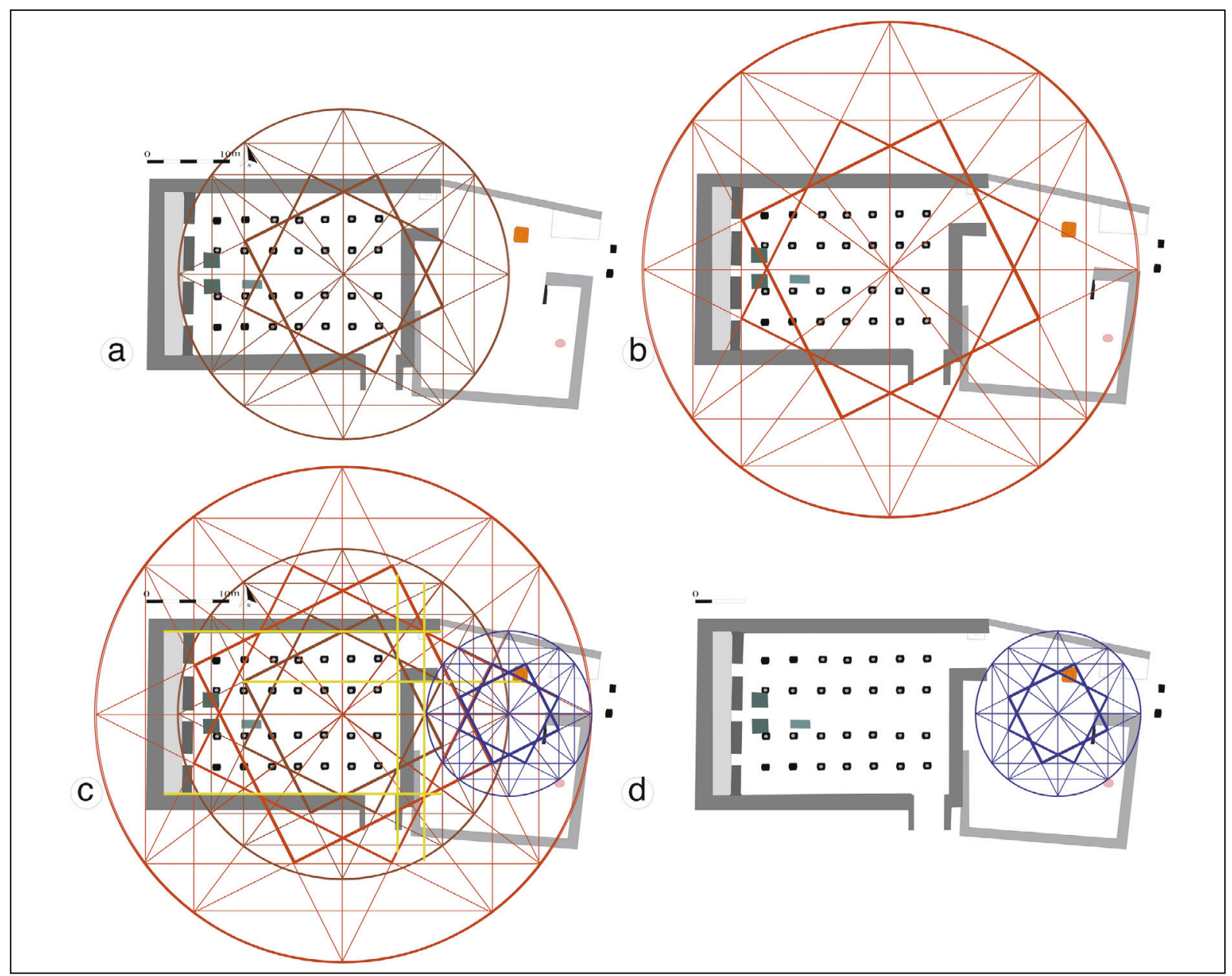

Figura 20. El codo de $50 \mathrm{~cm}$ en el templo de Astarté de Kition

Figure 20. The $50 \mathrm{~cm}$ cubit in the temple of Astarte of Kition

producirse en los límites exteriores de la construcción en donde, esta vez, se ajustaría mejor un codo de $0,50 \mathrm{~m}$ sobre estrellas de ocho y doce veces el tamaño utilizado como unidad (figura 20, a y b).

Si bien el témenos, situado al este de la construcción, viene definido morfológicamente por los elementos situados en esta área en la Edad del Bronce, la ubicación del altar, así como otros elementos que lo caracterizan, pueden definirse mediante una estrella cuatro veces el tamaño del módulo, de codo de o,50 m (figura I9, d). El centro de esta estrella se posiciona en el vértice este de la estrella ocho veces el tamaño unidad, coincidiendo su vértice este con el de la estrella doce veces el tamaño base (figura 20, c), dando coherencia al diseño.

El hecho de utilizar diferentes tamaños de codo puede deberse a que los elementos que conforman la construcción se definen en momentos distintos.

\subsection{El Templo de Ain Dara}

Elegimos como referencia el Templo de Ain Dara, al haber podido servir como modelo para la arquitectura sacra levantina (Novák, 20I2: 52) y debido a su similitud con el Templo de Salomón (Novák, 2OI2: $\left.4 \mathrm{I}^{-} 42,5 \mathrm{I}^{-}-52\right)$, aun sabiendo que este corresponde a un momento anterior a La Rebanadilla y que, culturalmente, por morfología y decoración, sería Neo-Hitita (Novák, 20I2).

Para su estudio se ha utilizado como base el plano publicado por Novák (20I2: fig. 4), dibujo realizado por Elsen-Novák sobre el publicado por Abū Assāf (I990: abb. I8).

El edificio estaba orientado en el eje sureste-noroeste, y corresponde al tipo de templum in antis, al que se accedería por una escalera, con la entrada flanqueada por columnas. En el recibidor de 


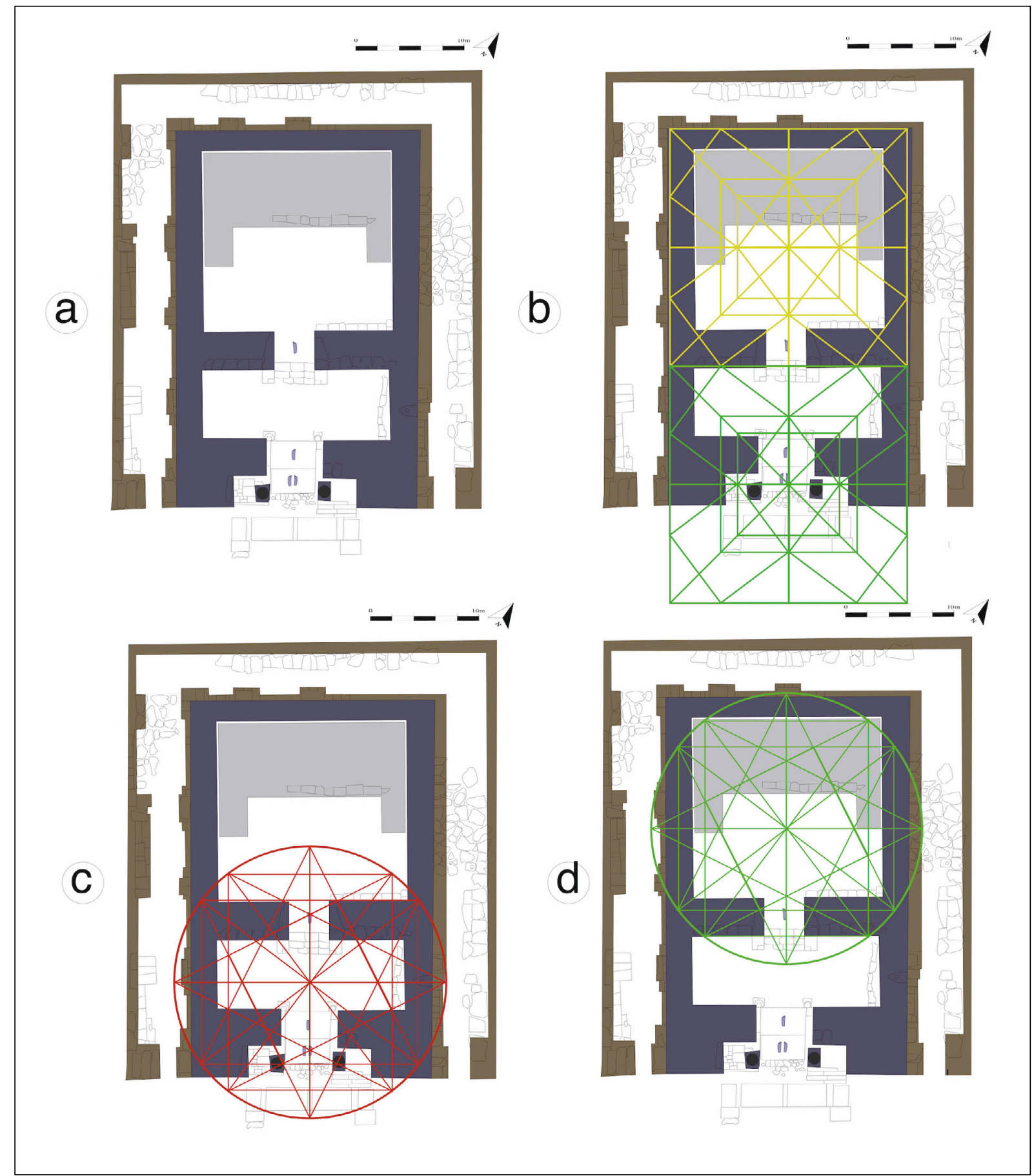

Figura 21. El diseño interior del templo de Ain Dara

Figure 21. The interior design of the Ain Dara temple

acceso a la antecámara, y en el corredor de acceso a la sala principal, se observan huellas de pies de grandes dimensiones talladas en el suelo; los muros principales presentan contrafuertes, y el núcleo de la construcción estaría rodeado por un corredor (Novák, 20I2: 47-48). El área sagrada se encontraría al fondo del edificio, sobre una plataforma elevada.
El análisis de la planimetría nos muestra la utilización del codo de $0,52 \mathrm{~m}$ para la delimitación de los volúmenes de las diferentes salas y elementos que definen el núcleo de la construcción. Para ello se han utilizado dos figuras en forma de aspa de tres veces el tamaño utilizado como unidad (figura 2I, b). La primera de ellas delimita los elementos existentes en la 


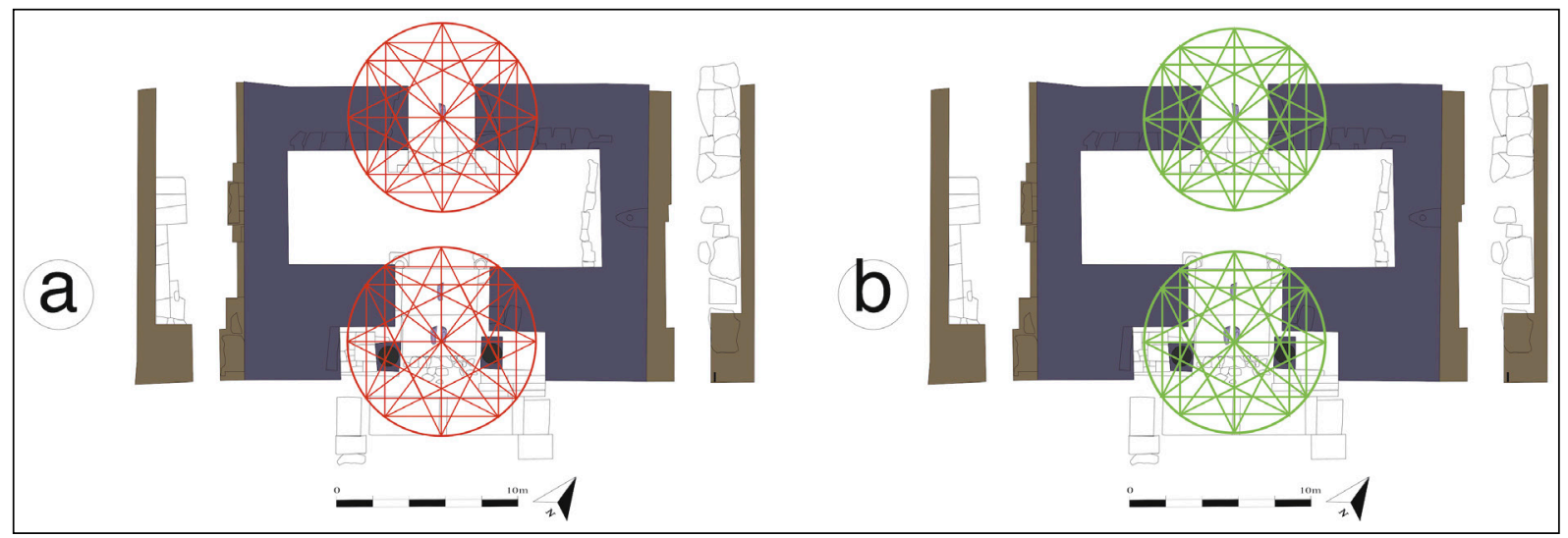

Figura 22. El diseño de la puerta del templo de Ain Dara

Figure 22. The design of the gate of the Ain Dara temple

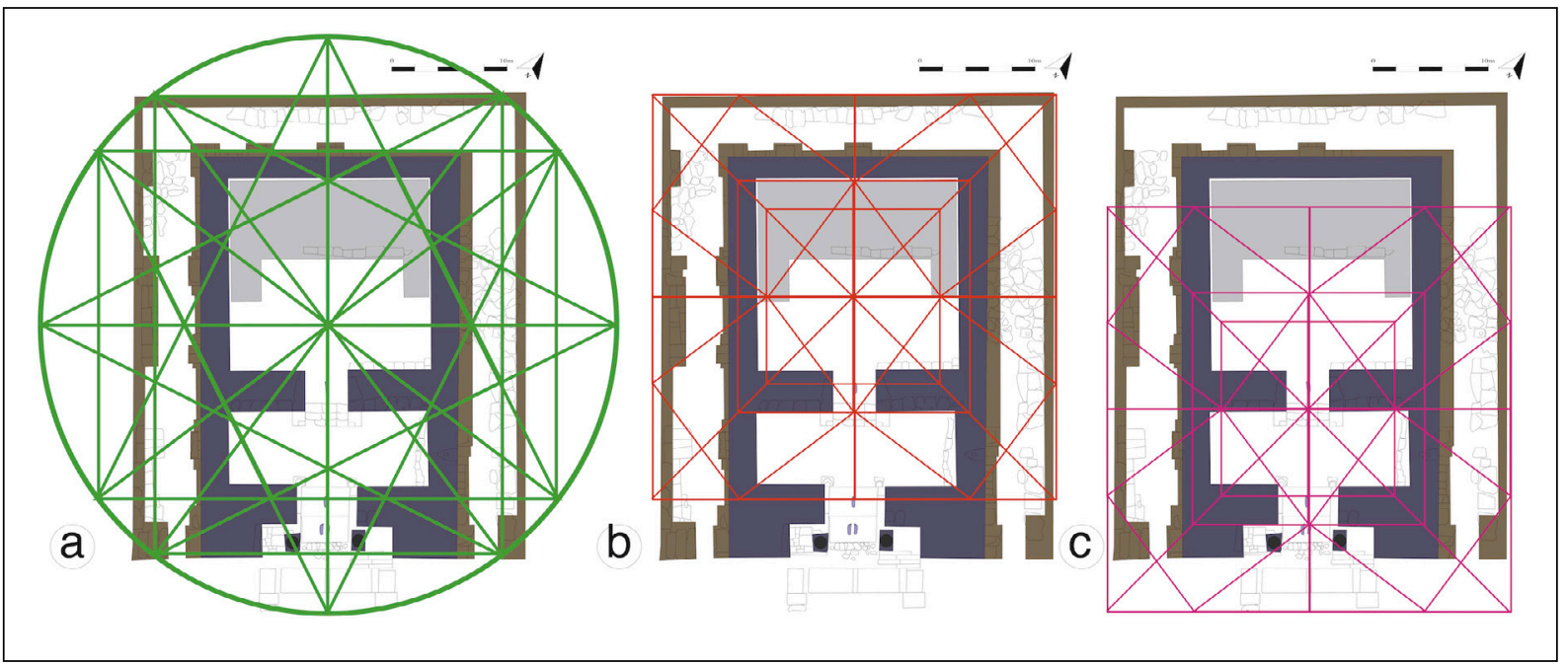

Figura 23. El diseño del corredor exterior y la utilización de la forma de aspa en el templo de Ain Dara

Figure 23. The design of the outer corridor and the use of the cross shape in the Ain Dara temple

entrada, la escalera, las columnas o el ancho del recibidor, así como las medidas de la antecámara. Destaca que el centro de la figura se sitúa sobre el talón de la huella derecha del par existente en la entrada.

La segunda figura en forma de aspa se ubica directamente sobre la anterior, definiendo los límites de la sala principal y la plataforma sagrada.

El diseño parece completarse con dos estrellas de cinco veces el tamaño del módulo, esta vez construidas en base a un codo de $0,50 \mathrm{~m}$. Si bien es chocante la utilización de dos tamaños diferentes de codo, esta modelización tiene la particularidad de que los puntos de la estrella que define la entrada, en donde se cruzan los dos triángulos isósceles orientados en el eje aproximado este-oeste, se colocan encima de las dos huellas de pies derechos (figura 2I, c).
Igualmente, la estrella que define el área sagrada de la construcción parece ubicarse en función de la huella derecha situada en el corredor de acceso a la sala principal.

En un segundo nivel de diseño, de mayor detalle, podemos definir los principales elementos de la entrada y del pasillo de entrada a la sala principal por medio de una estrella del doble del tamaño de la unidad. Debido al tamaño, no es fácil definir el módulo del codo empleado, ya que la diferencia entre la estrella de o, $52 \mathrm{~m}$ (figura 22, a) y la de $0,50 \mathrm{~m}$ (figura 22, b) son $40 \mathrm{~cm}$. Aún así, las estrellas construidas con un codo de $0,50 \mathrm{~m}$ parecen ajustarse mejor a la escalera de entrada y al tamaño del recibidor y pasillo, aunque solamente podríamos determinarlo mediante nuevas mediciones más precisas. 


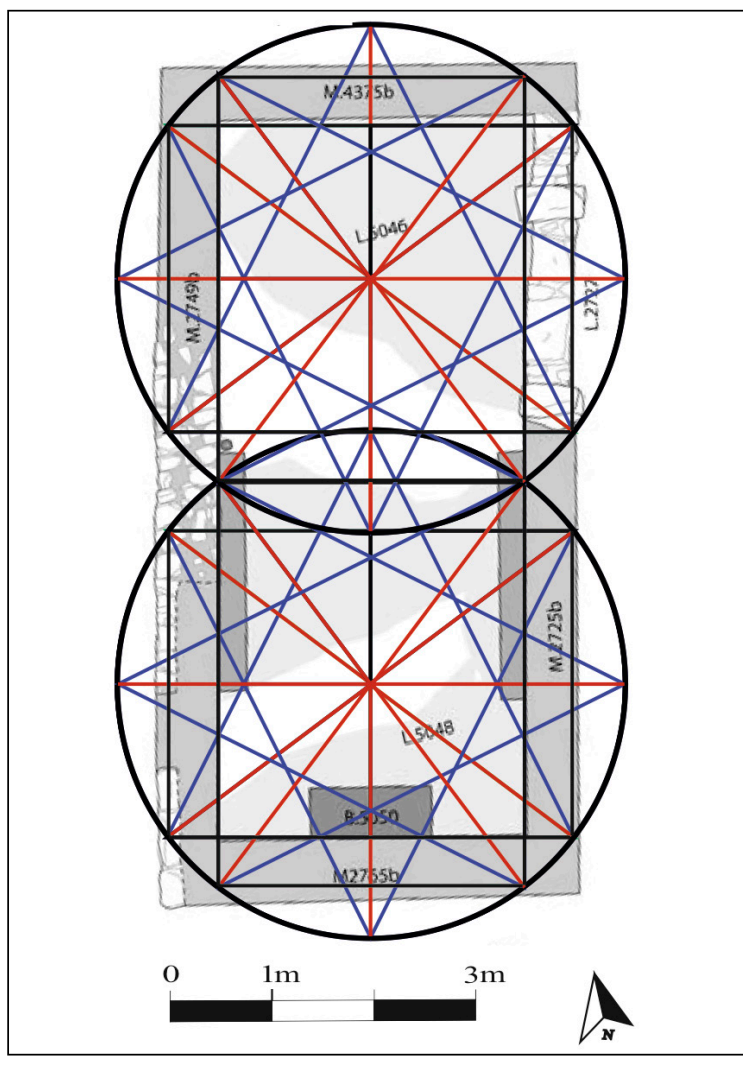

Figura 24. El templo de Astarté de Mozia

Figure 24. The Astarte temple of Motya

El corredor exterior, y los refuerzos existentes en su interior, se definen perfectamente por medio de la combinación de una figura con forma de estrella de diez veces la unidad, con dos figuras en forma de aspa de cinco veces el tamaño del módulo; todas ellas posicionadas en función de las huellas talladas en el suelo (figura 23).

El papel de las huellas en la ubicación de las diferentes figuras utilizadas para la modelización de la planimetría nos hace pensar que, además de un carácter simbólico, tenían la función de determinar los módulos de la construcción. Sería necesario contar con medidas exactas de la misma para observar si su tamaño puede fijar el del codo utilizado en la construcción, como ocurría con el triangulo existente en la rampa de acceso a El Carambolo V.

\subsection{Un último ejemplo del Mediterráneo Central: el Templo de Astarté de Mozia}

La elección del Templo de Astarté de Mozia fue debida a que presentaba características similares al
Templo 1 de La Rebanadilla, como son su orientación o su unicelularidad, y a la necesidad de verificar el modelo con edificios centro-mediterráneos. La planimetría utilizada para el estudio es la publicada por Nigro (2018: fig. 5).

El templo se compone de una única estancia, con la entrada, con umbral monolítico, situada en el extremo norte del muro este, con bancos corridos adosados a los muros largos, y con hogar/altar adosado al muro sur (Nigro, 20I8: 258).

Este edificio parece quedar articulado por dos figuras en forma de estrella de tamaño igual al módulo, con codo de $0,50 \mathrm{~m}$, que se relacionan entre sí al apoyarse el vértice del triángulo de la figura sur sobre la base del triángulo de la estrella situada en la parte norte. De esta forma, se definen la ubicación de los muros y su grosor, el umbral monolítico, el ancho de los bancos corridos y la posición del hogar/altar adosado al muro sur (figura 24).

\section{Conclusiones}

Los edificios presentados en estas páginas muestran dimensiones y proporciones coincidentes con las dos figuras básicas de diseño generadas a partir del triángulo $3 / 4 / 5$ : la figura en forma de estrella construida con triángulos isósceles, inscrita en una circunferencia; y la figura con forma de aspa realizada a partir de los cuadrados del triángulo rectángulo $3 / 4 / 5$, e inscrita en un cuadrado. Son, por tanto, la base del diseño de los edificios estudiados que, combinadas o superpuestas, mejoran el detalle y la definición del proyecto constructivo en el que se definen.

En muchos de los edificios analizados se aprecian varios niveles de diseño: uno que define las características fundamentales de los volúmenes y espacios de la edificación y otro, de mayor detalle, normalmente de las estancias cargadas de una significación especial o ritual, que se encarga de definir, con más precisión, sus características, así como la ubicación de los elementos rituales.

Los elementos cargados de una significación ritual, como son los hogares, hogares/altares, mesas/altares y pozos, son puntos centrales en la planificación del edificio. En varios de los casos pueden estar 
construidos en base a triángulos rectángulos $3 / 4 / 5$ con la figura en forma de estrella, como son la piscina/hogar del Templo 2 de La Rebanadilla, el hogar de la Capilla 2 de La Rebanadilla, o la rampa de entrada a El Carambolo V. Esta puede, también, ser punto central desde la que se articula el diseño completo de la estancia, como ocurre en la entrada de E1 Carambolo V, o en las huellas gigantes del Templo de Ain Dara; pero también puede encontrarse en posiciones ligeramente descentradas, como en las tangentes al eje, o ejes principales de simetría, en especial en los niveles de mayor grado de detalle del diseño: Templo 1, Templo 2 y Capilla 2 de La Rebanadilla, o en la mesa de ofrendas del Templo de Astarté de Kition.

Otros elementos rituales, que pudieran parecer descentrados o fuera de sitio, en realidad los encontramos en las cercanías de los puntos en donde se cortan los lados de los triángulos isósceles de la figura de estrella, en ocasiones remarcados por estas líneas. Esto sugiere que estos puntos deben estar cargados de una significación especial que les hace propicios para la ubicación de elementos rituales, como el hogar y el hogar/altar de la habitación situada al suroeste en El Carambolo V, la piscina/hogar y el hogar del patio del Templo 2 de La Rebanadilla, o el hogar/altar del témenos del Templo de Astarté de Kition. Igual función parece que cumple el rombo, formado por los triángulos rectángulos, situado en el interior de la forma de aspa, como el Templo 2 de La Rebanadilla que alberga el hogar/altar en forma de piel de toro.

Las dos formas geométricas (seguramente porque parten de un mismo elemento en su construcción) se relacionan entre sí en el hecho de que comparten el mismo centro: la que consideramos unidad de la que tiene forma de aspa, y la del doble del módulo de la que tiene forma de estrella, ambas quedan inscritas en la misma circunferencia. Igualmente, la distancia en los ejes de simetría del cuadrado en el que se inscribe la forma de aspa, es muy próxima al tamaño de la circunferencia del triángulo en el que se puede inscribir el representado en la entrada de El Carambolo V; es decir, el que era $1 / 7$ del doble del módulo; por lo que su colocación en E1 Carambolo V, en donde se relacionan las dos formas,

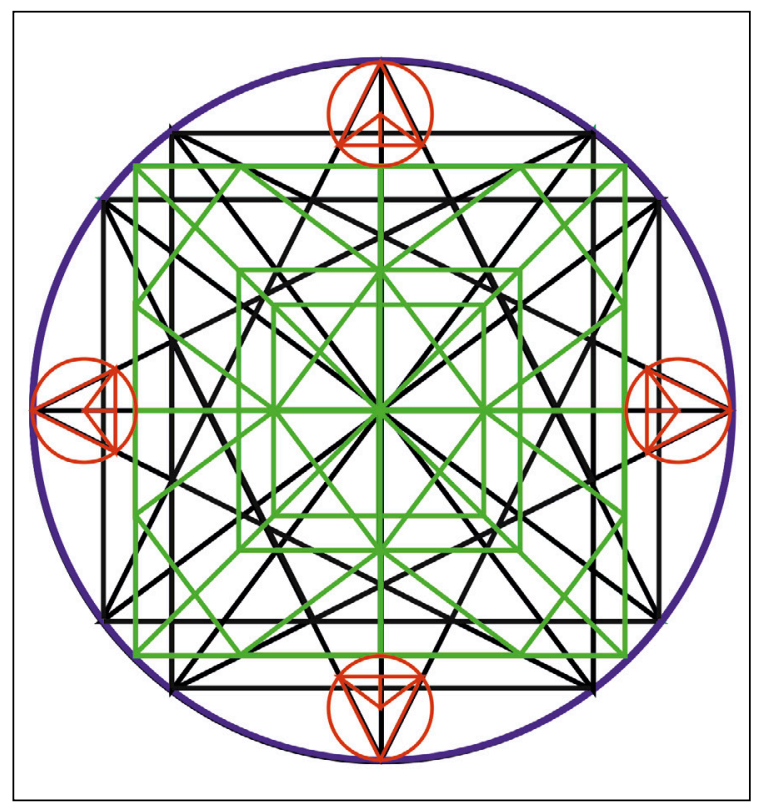

Figura 25. La relación entre la aspa y la estrella

Figure 25. The relationship between the cross and the star

al igual que en los otros edificios, es una clara exposición, por parte de los arquitectos fenicios, de la existencia de un conocimiento geométrico y un diseño previo de los edificios (figura 25).

Los fenicios tendrían los conocimientos para llevar los bocetos al terreno por medio de la cuerda de I2 nudos y sus múltiplos, ya que con ella podrían dibujar, en el terreno, los elementos necesarios del diseño. Aunque muchas veces observamos pequeñas y grandes desalineaciones en todos los edificios, como decía Rossi, estos podrían deberse a los errores que esta técnica acumularía para pequeñas distancias, por el grosor de la cuerda y de los nudos.

Como ya comentó Escacena (2016: 50), construir con muros rectos supone dominar las técnicas para trabar bien las esquinas, y los conocimientos matemáticos para el diseño de los ángulos rectos. Estos conocimientos matemáticos quedan de manifiesto en el análisis de los edificios, ya que permiten ver que los arquitectos fenicios utilizan los triángulos 3/4/5 como base para la construcción de las demás formas geométricas empleadas en el diseño de las construcciones: triángulos isósceles, cuadrados, rombos y círculos.

E1 módulo del codo sobre el que se ha trabajado es de $0,50 \mathrm{~m}$, a excepción de alguna de las fases del Templo de Astarté de Kition y el Templo de 
Ain Dara, en donde se observa que es de $0,52 \mathrm{~m}$ y de $0,54 \mathrm{~m}$, normalmente correspondiendo con los elementos más antiguos. Sería factible que este se pudiera ajustar con mayor precisión, ya que para los edificios que no se localizan en La Rebanadilla se ha trabajado sobre planimetrías previamente publicadas, siendo la diferencia entre una estrella base de codo de $0,50 \mathrm{~m}$, y otra de $0,54 \mathrm{~m}$, de $40 \mathrm{~cm}$ en el diámetro del circulo en el que se inscribe.

\section{Bibliografía}

Abū Assāf, A. (1990): Der Tempel von Ain Dārā. Damaszener Forschungen, 3. Zabern Verlag. Mainz am Rhein.

Arancibia, A., Galindo, L., Juzgado, M., Dumas, M. y Sánchez, V.M. (20II): "Aportaciones de las últimas intervenciones a la arqueología fenicia de la Bahía de Málaga”. En M. Álvarez Martí-Aguilar (ed.): Fenicios en Tartessos: nuevas perspectivas. British Archaeological Reports International Series, 2245. Archaeopress. Oxford: I29-I49.

Arteaga, O. (200I): “La 'Polis'Malacitana. Una aproximación desde la economía política, las relaciones interétnicas, y la política económica referida al intercambio comercial". En F. Wulf, G. Cruz y C. Martínez (eds.): II Congreso de Historia antigua de Málaga. Comercio y comerciantes en la Historia antigua de Málaga (Siglos VIII a.C.-año 7II d.C.). Diputación de Málaga. Málaga: 203-275.

Aubet, M.E., Carmona, P., Curià, E., Delgado, A., Fernández, A. y Párraga, A. (1999): Cerro del Villar I. El asentamiento fenicio en la desembocadura del rio Guadalhorce y su interacción con el binterland. Junta de Andalucía. Sevilla.

Belmonte,J.A. (1999): Las leyes del Cielo. Astronomia y Civilizaciones Antiguas. Temas de Hoy. Madrid.

\section{Agradecimientos}

Quisiera dar las gracias a Arqueoestudio S.Coop. y, en especial, a Lorenzo Galindo San José, por apoyarme y ayudarme a lo largo de estos años en este proyecto; a Rebeca C. Recio Martín por sus correcciones y aportaciones, así como al profesor Alfredo Mederos Martín que siempre me aconseja, apoya, ayuda y colabora en la realización de los trabajos sobre La Rebanadilla. Este artículo se encuadra en los estudios realizados para la tesis doctoral sobre el yacimiento fenicio arcaico de La Rebanadilla.

Benito Muñoz, M., Fernández Moral, E. y Marqués López, J.L. (2004): "Dos notas históricas sobre ternas pitagóricas”. En L. Español González, J.J. Escribano Benito y M.A. Martínez García (eds.): Actas VIII Congreso de la Sociedad Española de Historia de las Ciencias y de las Técnicas (Logroño, 2002). Sociedad Española de Historia de las Ciencias y de las Técnicas. Logroño: 331-345.

Braemer, F. (1982): L'architecture domestique du Levant à l'Age du Fer. Éditions Recherche sur les civilisations. Paris.

Briend, F. y Humbert, J.B. (1980): Tell Keisan (I97I-I976), une cité phénicienne à Galilée. Orbis Biblicus et Orientalis. Serie Archeologica, I. Éditions Universitaires. Paris

Delgado Hervás, A. (2008): "Cerro del Villar, de enclave comercial a periferia urbana: dinámicas coloniales en la bahía de Málaga entre los siglos viII y vi a.C.”. En D. García i Rubert, I. Moreno Martínez y F. Gracia Alonso (eds.): Contactes. Indígenes i fenicis a la Mediterrània occidental entre els segles VIII $i$ VI ane (Alcanar, 2006). GRAP. Barcelona: 69-88.

Díes Cusí, E. (1994): La arquitectura fenicia de la Peninsula Ibérica y su influencia en las culturas indigenas. Tesis doctoral. Facultad de Geografia i Historia, Universitat de València. Valencia. 
Díes Cusí, E. (200I): "La influencia de la arquitectura fenicia en las arquitecturas indígenas de la Península Ibérica (S.viII-viI)”. En D. Ruiz Mata y S. Celestino Pérez (eds.): Arquitectura oriental y orientalizante en la Peninsula Ibérica. CSIC-CEPO. Madrid: 69-I22.

Edrey, M. (2018) "Towards a Definition of the PreClassical Phoenician Temple". Palestine Exploration Quarterly, 150 (3): 184-205. <doi: I0.1080/00310328.2018.I471652>.

Escacena Carrasco, J.L. (2016): "Dioses, Toros y A1tares. Un templo para Baal en la antigua desembocadura del Guadalquivir". En E. Ferrer (ed.): Ex Oriente Lux: las religiones orientales antiguas en la peninsula ibérica. SPAL monografias 2. Universidad de Sevilla. Sevilla: 33-75.

Fernández Flores, A.y Rodríguez Azogue, A. (2007): Tartessos desvelado. La colonización fenicia del suroeste peninsular y el origen y ocaso de Tartessos. Almuzara. Córdoba.

González de Canales Cerisola, F., Serrano Pichardo, L. y Llompart Gómez, J. (2004): El emporio fenicio precolonial de Huelva (ca. 90o-77o a.C.). Biblioteca Nueva. Madrid.

Hunt Ortiz, M.A., Montero Ruiz, I., Rovira Llorens, S., Fernández Flores, A. y Rodríguez Azogue, A. (2010): "Estudio arqueométrico del registro de carácter metálico de las campañas 2002-2005 en el yacimiento de 'El Carambolo". En M.L. de la Bandera Romero y E. Ferrer Albelda (eds.): El Carambolo. 50 años de un tesoro. Universidad de Sevila. Sevilla: 27I-293.

Kamlah, J. (2009): "Die Tempel und Heiligtümer Phöniziens: Kultstätten im Kontext der eisenzeitlichen Stadtkultur in der Levante”. En S. Helas y D. Marzoli (eds.): Phönizisches und punisches Städtewesen (Rom, 2007). Philip von Zabern. Mainz: 83-98.

Karageorghis, V.(1976): Kition: Mycenaean and Phoenician discoveries in Cyprus. Thames \& Hudson. London.

López Castro, J.L. (2012): "Fenicios en el Mediterráneo: Modelos de relaciones interculturales". En J.M. Jiménez Arenas y F.A. Muñoz Muñoz (eds.): La Paz, patera de la historia. Editorial de la Universidad de Granada. Granada: 87-97.
López Castro,J.L. (2005): "Aristocracia fenicia y aristocracias autóctonas. Relaciones de intercambio". En S. Celestino Pérez y J. Jiménez Ávila (eds.): El Periodo Orientalizante I. Anejos de Archivo Español de Arqueología, XXXV. IAM-CSIC. Mérida: 405-421.

López Pardo, F. (1990): "Sobre la función del edificio singular de Cancho Roano (Zalamea de la Serena, Badajoz)”. Gerión, 8: I4I-I62.

Margueron, J. (199I): "Sanctuaires semitiques". Supplément au Dictionnaire de la Bible Fasc. $64 \mathrm{~B}-65$ : I216-1256.

Martínez Ortega, A. (200I): "El diseño de pirámides basado en el triángulo sagrado egipcio". Boletín de la Asociación Española de Egiptología, II: 7-I9.

Marzoli, D., Banerjee, A., Sánchez, V.M.y Galindo, L. (2016): "Elfenbeinwerkstätten in Huelva und La Rebanadilla (Málaga), den ältesten phönizischen Niederlassungen auf der Iberischen Halbinsel”. Madrider Mitteilungen, 57: 88-138.

Montet, P. (I964): «Le rituel de fondation des temples égyptiens». Kémi, I7: 75-100.

Nigro, L. (2018): "La Sapienza a Mozia 2010-20I6: il primo insediamento fenicio, l'area sacra di Baal e Astarte, il Tofet, la necropoli,l'abitato, i nuovi scavi alle mura - una sintesi”. Folia Phoenicia, 2: 253-277.

Nissinen, M. y Münger, S. (2009): “Down the River...': A Shrine Model from Tel Kinrot in its Context". En E. Kaptijn y L.P. Petit (eds.): $A$ timeless vale: archaeological and related essays on the Jordan Valley in honour of Gerrit van der Kooij on the occasion of his sixty-fifth birthday. Leiden University Press. Leiden: I29-I44.

Novák, M. (20I2): "The Temple of Ain Dâra in the Context of Imperial and Neo-Hittite Architecture and Art”. En J. Kamlah (ed.): Temple Building and Temple Cult. Architecture and Cultic Paraphernalia of Temples in the Levant (2.-I. Mill. B.C.E.) (Tübingen, 2010). Abhandlungen des Deutschen Palästina-Vereins, 4r. Harrassowitz Verlag. Wiesbaden: 4I-54.

Osuna, M., Bedia, J. y Domínguez, A.M. (2000): “El santuario protohistórico hallado en la calle Méndez Núñez (Huelva)". En P.Cabrera y M. Santos (eds.): Ceràmiques jònies d'època arcaica: centres de producció $i$ comercialització al Mediterrani Occidental (Empùries, 1999). Monografies Emporitanes, Ir. Museu d'Arqueologia de Catalunya. Empùries: I77-I88. 
Perra, C. (1998): L'architettura templare fenicia e punica di Sardegna: Il problema delle origini orientale. S'Alvure. Oristano.

Prados Martínez,F. (2010): "La arquitectura sagrada: un santuario del siglo ix a.C.”. En L. Berrocal-Rangel y A.C. Silva (eds.): O Castro dos Ratinhos (Barragem do Alqueva, Mora). Escavaçôes num povoado proto-histórico do Guadiana, 2004-2007. O Arqueólogo Português Suplemento, 6. Museu Nacional de Arqueologia. Lisboa: 259-276.

Rossi, C. (2007): Arcbitecture and Mathematics in Ancient Egypt. Cambridge University Press. Cambridge.

Sánchez, V.M., Galindo, L. y Juzgado, M. (2020): "El santuario fenicio de La Rebanadilla". En J.L. López Castro (ed.): Entre Utica y Gadir. Navegación y colonización en el Mediterráneo Occidental a comienzos del I Milenio AC. Comares. Granada: 189-200.

Sánchez, V.M., Galindo, L., Juzgado, M.y Belmonte, J.A. (2018): "La Rebanadilla, santuario litoral fenicio en el Sur de la Península Ibérica”. En M. Botto (ed.): De Huelva a Malaka. Los fenicios en Andalucia a la luz de los descubrimientos más recientes. Collezione di Studi Fenici, 48. Consiglio Nazionale delle Ricerche. Roma: 305-323.
Sánchez, V.M., Galindo, L., Juzgado, M. y Dumas, M. (20I2): "El asentamiento fenicio de 'La Rebanadilla' a finales del siglo Ix a.C.”. En E. García Alfonso (ed.): Diez años de arqueología fenicia en la provincia de Málaga. CD-ROM. Junta de Andalucía. Sevilla: 67-86.

Sánchez, V.M., Galindo, L., Juzgado, M. y Dumas, M. (20II): "La desembocadura del Guadalhorce en los siglos ix y viII a.C. y su relación con el Mediterráneo". En J.C. Domínguez Pérez (ed.): Gadir y el Circulo del Estrecho revisados. Propuestas de la arqueología desde un enfoque social. Editorial UCA. Cádiz: 185-200.

Wright, G.R.H. (1985): Ancient Building in South Syria and Palestine. I-II. Brill. Leiden. 